\title{
POPULATION DYNAMICS AND PRODUCTIVITY OF ZOOPLANKTON IN TWO SANDHILLS LAKES
}

\author{
By
}

PAUL E. MASLIN

\begin{abstract}
A DISSERTATION PRESENTED TO THE GRADUATE COUNCIL OF THE UNIVERSITY OF FLORIDA

IN PARTIAL FULFILLMENT OF THE REQUIREMENTS FOR THE DEGRE OF DOCTOR OF PHILOSOPHY
\end{abstract}

UNIVERSITY OF FLORIDA

1969 


\section{ACKNOWLEDGMENTS}

I would like to express my apprectation to the many people who have assisted in this study.

The co-chairmen of my advisory committee, Drs. Robert DeWitt and Frank Nordlie, have offered guidance and helpful criticism throughout the research as well as in the preparation of the manuscript. The other members of my committee, Drs. Brian McNab, John Kaufmann, and Hugh Putnam, have edited and advised in the preparation of the report. The participants in the Lake Study Project of the Environmental Engineering Department have provided me with free use of their lake facilities as well as with much limnological data.

Several graduate students, particularly Carl Colson and Richard Fox, helped in collecting the samples.

My wife, Karolyn Maslin, helped in collecting all samples and editing of the dissertation as well as lending moral support throughout the study.

The FWPCA, through training grant 5T1-WP-1119-02 and research grant 16010DON, provided financial assistance without which this study would have been Impossible. 


\section{TABLE OF CONTENTS}

Acknowledgments

List of Tables

List of Figures

vi

Introduction

Materials and Methods

Sampling

Determination

Secondary Production

Predation

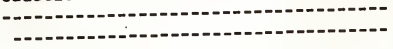

Statistics

Resu1ts

Population Density

17

17

Biomass

\section{De}

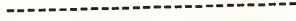

Changes in Lake Anderson-Cue

General Population Dynamics
Relationship of Temperature to Zooplankton

Food Limitation

-- - - - - - - - - - -

Species Interactions

Production
Predation

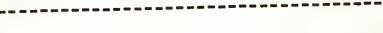

Discussion

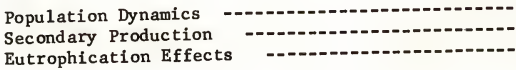

Summary

37

39

42

50

66

74

74

Literature Cited

Biographical. Sketch 


\section{LIST OF TABLES}

\section{Table}

1. Chemical Characteristics of Anderson-Cue and McCloud Lakes

2. Population Densities (No. $/ \mathrm{m}^{2}$ ) of Zooplankton -Microcrustacea of Anderson-Cue, 1967

3. Population Densities (No. $/ \mathrm{m}^{2}$ ) of Zooplankton -Rotifera of Anderson-Cue, 1967

4. Population Densities (No. $/ \mathrm{m}^{2}$ ) of Zooplankton -Microcrustacea of Anderson-Cue, 1968

5. Population Densities (No. $/ \mathrm{m}^{2}$ ) of Zooplankton -Rotifera of Anderson-Cue, 1968

6. Population Densities (No. $/ \mathrm{m}^{2}$ ) of Zooplankton -Microcrustacea of McCloud, 1967

7. Population Densities (No. $/ \mathrm{m}^{2}$ ) of Zooplankton -Rotifera of McCloud, 1967

8. Population Densities (No. $/ \mathrm{m}^{2}$ ) of Zooplankton -Microcrustacea of McCloud, 1968

9. Population Densities (No. $/ \mathrm{m}^{2}$ ) of Zooplankton -Rotifera of McCloud, 1968

10. Dry Weight of Zooplankton 36

11. Frequency of Rarer Species as Related to Eutrophication

12. Mean Biomass of Zooplankton (mg/m $\left.{ }^{2}\right)$

13. Relative Stability of Populations 41

14. Relationship between Temperature and Zooplankton Biomass ( $r$ values)

15. Summer Changes in Zooplankton 
LIST OF TABLES - continued

Table

16. Frequency of Rarer Species as Related to Temperature 58

17. Relationship between Zooplankton and Chlorophyl1

18. Correlation of Zooplankton Biomass to Primary Productivity

19. Relationship between Temperature and Primary Productivity

20. Correlation Coefficients for Photoperiod Compared to Primary Productivity and Zooplankton Biomass

21. Numerical Dominance of Cladocera When Different Numbers of Species Were Present

22. Numerical Dominance of Cladoceran Species

23. Biomass Dominance of Cladoceran Species

24. Relationship of Temperature to Daphnia and Bosmina Biomass

25. Correlation Coefficients between Species in Lake Anderson-Cue

26. Correlation Coefficients between Species in Lake McCloud

27. Over-al1 Relationship between Species 71

28. Correlations between Biomass of Taxonomic Groups -.-- 73

29. Zooplankton Production $\left(\mathrm{g} \mathrm{m}^{-2}\right.$ year $\left.^{-1}\right)$

30. Production and Efficiency 76

31. Gut Contents of L. sicculus 77

32. Some Representative Rates of Secondary Production in Aquatic Ecosystems 


\section{LIST OF FIGURES}

Figure

1. Relationship of observed rate of increase " $r$ " to population density for Daphnia ambigua and Diaptomus floridanus

2. Seasonal changes in temperature and zooplankton biomass in the experimental lake in 1967

3. Seasonal changes in temperature and zooplankton biomass in the experimental lake in 1968

4. Seasonal changes in temperature and zooplankton biomass in the control lake in 1968

5. Seasonal distribution of copepod biomass in the experimental and control lakes

6. Seasonal distribution of cladocera biomass in the experimental and control lakes

7. Seasonal distribution of rotifer biomass in the experimental and control lakes

8. Annual variation of chlorophy 11 a in Anderson-Cue and $\mathrm{McCl}$ oud lakes

9. Annual variation of primary productivity in Anderson-Cue and McCloud lakes

10. Population fluctuations of cladocera in Lak Anderson-Cue following their summer disap- 


\section{INTRODUCTION}

Even though zooplankton has been a favorite subject of limnologists for the past half century, little work has been done in terms of population dynamics or productivity. Reports of population fluctuations are common but few have included an analysis of factors regulating zooplankton populations. A principal reason for this superficial analysis has been the difficulty of monitoring the many environmental variables which might affect zooplankton. I was fortunate in being able to participate in a lake eutrophication project directed by the University of Florida Environmental Engineering Department. In the resulting exchange of lake data, I obtained much valuable environmental information for correlation with zooplankton populations. The eutrophication project and this study involve two small lakes located in the sandhills region about five miles east of Melrose, Florida.

The Florida sandhills region consists of low, rolling hills with small lakes interspersed among them. The soil, of the Lakeland series, is derived from deep quartz sand and is extremely well leached (Laessle, 1958). The vegetation was originally longleaf pine (Pinus palustris) with an understory of turkey oak (Quercus laevis), but selective timbering has removed most of the pine, leaving turkey oak as the apparent dominant. The great porosity of the soil and the rolling topography virtually ensure against any surface runoff in even the heaviest rains. 
The numerous small lakes in the sandhills are typically oligotrophic, with soft, slightly acid water not much different in mineral content from rainwater. There are two aquifers associated with the sandhills: an upper perched aquifer in the sand underlain with clays, and a lower, very extensive artesian aquifer in the deeper lying 0cala limestone (Anonymous, 1968). The lakes are sealed in their deeper regions by sediments, but connected into the upper aquifer via the porous sand in the littoral areas. Accordingly, the lakes fluctuate with the upper aquifer except during conditions of drought when they become perched. The sandhills regions are important to the economy of Florida for three conflicting reasons. First they comprise the main recharge areas for the artesian aquifer upon which nearly all major Florida cities depend for water supply. Second the southern region of the sandhills is the heart of the orange growing area of Florida, where for miles all of the hills are covered with heavily fertilized groves. Third the welldrained land around the lakes is becoming increasingly popular for development of model communities, suburbs, etc. The cultural eutrophication of the sandhills lakes from fertilizer or domestic drainage could seriously impair the quality of Florida's ground water.

The lakes involved in this study are located on private property and receive very little cultural influence. They were initially very similar, being about the same size and only 0.4 miles apart, with the same type of surrounding soil and vegetation. Table 1 shows the similarity of chemical and physical parameters of the lakes at the start of the project. Since March, 1967, nutrients have been added to the experimental lake, Anderson-Cue, at rates comparable to nutrient loading 
rates known for eutrophic lakes. Nitrogen has been added at a rate of ca. $0.5 \mathrm{mg} \mathrm{N}^{-1}$ year $^{-1}$ and phosphorus at ca. $0.05 \mathrm{mg} \mathrm{P}^{-1}$ year $^{-1}$. These nutrients are added in the form of $\mathrm{NH}_{4} \mathrm{Cl}$ and $\mathrm{Na}_{3} \mathrm{PO}_{4}$ dissolved in secondary sewage effluent so some trace nutrients are being added. Lake McCloud has been kept as a control and comparable measurements of biological, chemical, and physical parameters have been made in both lakes. The variety and quantity of data available from the eutrophication study made these lakes an excellent area for the study of zooplankton population dynamics. Accordingly, I have attempted to monitor zooplankton populations and biomass and to correlate changes in the zooplankton with probable causative changes in other aspects of the ecosystem. In doing so I have used data collected by the Environmental Engineering staff for temperature (Figures 2-4), chlorophyll concentration (Figure 8 ), and primary productivity (Figure 9). I have also estimated zooplankton production to make comparisons between the 1 akes and with other ecosystems.

The study of fresh-water zooplankton began in this country with the descriptive and distributional work of Birge in the late 19 th century. It has progressed through seasonal population studies to population dynamics and finally in the late 1950's and 1960's to studies of production.

The number of seasonal studies of zooplankton is too great to permit discussion of each work. Most were quantitatively descriptive, determining variations in population size with time but making no effort to explain population changes other than classifying some organisms as being cold water or watm water forms. 
Table 1

Chemical Characteristics of Anderson-Cue and McCloud Lakes

\begin{tabular}{|c|c|c|c|c|c|c|}
\hline \multirow[b]{2}{*}{ Constituent $^{1}$} & \multicolumn{3}{|c|}{ Anders on-Cue } & \multicolumn{3}{|c|}{ McCloud } \\
\hline & Surf. & Mid. & Bottom & Surf. & Mid. & Bottom \\
\hline Specific Cond. & 28 & 28 & 27 & 32 & 30 & 31 \\
\hline $\mathrm{pH}$ & 4.7 & 4.8 & 4.7 & 4.9 & 4.8 & 4.7 \\
\hline Acidity & 3.4 & 3.2 & 3.4 & 3.6 & 3.7 & 4.5 \\
\hline Alkalinity & 0.8 & 0.7 & 0.7 & -- & -- & -- \\
\hline $\mathrm{Cl}^{-}$ & 5.0 & -- & 5.0 & 5.2 & --- & 5.5 \\
\hline $\mathrm{SO}_{4}=$ & 1.4 & 1.5 & 1.4 & 2.0 & 2.2 & 2.0 \\
\hline $\mathrm{Ca}^{+2}$ & 0,69 & 0.62 & 0,80 & 0,62 & 0.57 & 0.65 \\
\hline $\mathrm{Mg}^{+2}$ & 0.55 & 0.52 & 0.55 & 0.57 & 0.57 & 0.55 \\
\hline $\mathrm{Na}^{+}$ & 2.43 & 2.41 & 2.35 & 2.95 & 2.87 & 2.98 \\
\hline $\mathrm{K}^{+}$ & 0.48 & 0.53 & 0.53 & 0.28 & 0.23 & 0.26 \\
\hline
\end{tabular}

${ }^{1}$ Specific conductance in mho $\mathrm{cm}^{-1}$, acidity and alkalinity in $\mathrm{mg} / 1$ as $\mathrm{CaCO}_{3}$; other cations and anions in $\mathrm{mg} / 1$ (Anonymous, 1968). 
Other more recent papers have attempted to explain population changes in terms of environmental variables and to describe the ecology of individual plankton species. Pennington (1941) first suggested a relationship of phytoplankton to zooplankton. Pennak (1946, 1949) attempted to relate food to the zooplankton populations but concluded that phytoplankton was probably not the most important food source. This conclusion has not been accepted by subsequent workers such as Gauld (1950, 1951), Gibor (1956), Davis (1958), and George (1966) who have indicated there is a strong relationship between phytoplankton and zooplankton. Further support for phytoplankton being the chief food of zooplankton and also the probability that the relationship between phytoplankton and zooplankton is not one-sided (1.e., grazing by zooplankton may affect both the numbers and species of phytoplankton in a community) has been given by Martin (1965) and Krishnamoorthi and Visvesvara $(1963,1966)$. Ryther (1954) demonstrated that, in adequately dense cultures, the effect of phytoplankton on zooplankton may take the form of antibiosis. In 1954, Davis summarized the earlier literature on causes of population variation in zooplankton and discussed the lack of consistency and poor general correlations in terms of multiple factor causes.

Some laboratory studies have been very important in understanding zooplankton population dynamics. The first was a study by Ingle, et al. (1937) showing effects of food limitation on Daphnia reproduction and longevity. Another early study (Pratt, 1943) showed that generation time was directly related to temperature but potential population size was greater at lower temperatures. More recently Frank 
(1952, 1957, 1960) and Parker (1960, 1961) have demonstrated effects of competition on laboratory populations showing that two species even of different genera may be unable to coexist. Probably the laboratory study having the most bearing on natural population dynamics is that of Slobodkin (1954) demonstrating that populations cannot reach environmental equilibrium unless the environment remains constant for a period of time which may require several generations. Slobodkin also demonstrated that equilibrium population size is directly related to food supply and that environmental changes cause population changes only after time lags.

Recent studies have attempted to apply laboratory techniques and principles to natural populations. Most of these have dealt with only one species of the assemblage of zooplankters. Comita and Anderson (1959) found that reproductive rate in Diaptomus ashlandi was positively correlated with chlorophyll concentration. Edmondson (1962, 1965) and Edmondson, et al. (1962) have shown a similar positive relationship between food and reproduction in rotifers and copepods. There have been several attempts to bufld models for natural populations using life-table data based on comparisons with laboratory populations, the most notable befing those of Smith (1963) and Hall (1964). Hall found that his experimentally determined birth rates would predict spring and fall populations of Daphnia galeata mendotae but gave much too high predictions for the summer. He concluded that death rate', probably due to predation, was much greater in summer.

Attempts at measuring zooplankton production are also recent. Earlier workers such as Elster (1955) and Davis (1958) did not distinguish between standing crop and production. One of the first 
attempts to determine zooplankton production was an excellent study by Wright (1958). He made accurate calculations of zooplankton standing crop from counts of each species and mean dry weight per individual of a species, determining production from changes in standing crop and turnover rates. Unfortunately his study covered only two months. Stross, et a1. (1961) used total zooplankton biomass and turnover time for the dominant species to calculate zooplankton production. Their estimates are crude due to error in determining biomass; they weighed net catches assuming that the net would retain all zooplankton and pass all phytoplankton. Ilkowska et al. (1966) used reproductive rates and wet weights based on volume to calculate zooplankton production. Shuskina (1966a, 1966b) has devised a mathematical formula for calculating secondary production from zooplankton biomass; this me thod is at best an approximation. Chemyr (1966) has attempted to extend the use of carbon-14 to include measurements of secondary production but his method ignores respiration in both phytoplankton and zooplankton. Most recent1y, McAllister (1969) has made calculations of secondary production based on primary production, changes in phytoplankton standing crop and correction factors for zooplankton assimilation.

While there have been few direct studies showing changes in species composition and abundance with changes in the trophic nature of a lake, faunal comparisons of different lakes as by Lang (1931) and sediment studies such as those by Deevey (1942) and Goulden (1964) strongly suggest that such changes do occur. There have been several fertilization experiments involving fish ponds: Hepher (1962) found increased primary productivity up to a compensation point following fertilization, and Glonti and Tskhomelidze (1963) found an increase in 
zooplankton biomass. There have been two related experiments with lakes. Stross and Hasler (1960) and Stross, et.al. (1961) reported that lime added to a bog lake caused no increase in zooplankton standing crop but apparently caused a more rapid turnover resulting in increased production. Nelson and Edmondson (1955) reported that Inorganic fertilizer applied to Bare Lake, Alaska, induced an increase in primary production, no change in zooplankton biomass but again, presumably, an increase in turnover rate and thus in secondary production.

The present study will evaluate the interrelationships of zooplankton populations and environmental factors in Anderson-Cue and McCloud lakes with respect to food limitation, competition, predation upon, and production by zooplankton. 


\section{MATERIALS AND METHODS}

\section{Sampling}

Zooplankton samples were taken from January, 1967, through December, 1968, in Lake Anderson-Cue and from May, 1967, through December, 1968, In Lake McCloud. From January to August, 1967, samples were taken biweekly with a Wisconsin closing plankton net (125 meshes/inch) towed horizontally for a known distance at three depths corresponding to just below the surface, mid-depth and just above the bottom. Aliquots from these samples were counted; counts were adjusted to No. $/ \mathrm{m}^{3}$ and integrated over depth to obtain No. $/ \mathrm{m}^{2}$. After August, 1967, weekly samples were taken with a vertical-tow plankton net (125 meshes/ inch) pulled from bottom to surface. When using the vertical-tow net, samples were taken from three stations in the lake and each sample concentrated to $35 \mathrm{ml}$. The three samples were combined, mixed thoroughly, and a subsample of $35 \mathrm{ml}$ taken from the mixture for preservation with formalin and counting. This procedure provided a physical means of averaging samples from three areas of the lake while counting only one sample, thus providing a more representative sample from the lake.

Zooplankters were counted using a compound microscope at a magnification of 21 diameters. Each sample was shaken thoroughly; a $1 \mathrm{~m} 1$ aliquot was then taken with a graduated syringe and placed in a Sedgewick-Rafter counting chamber. Three such aliquots were counted for each sample and all zooplankters in the chambers were identified and 
counted. Occasionally, when phytoplankton was especially numerous, it was necessary to dilute a sample before counting. Counts from samples taken with a vertical-tow net were converted directly to No. $/ \mathrm{m}^{2}$ based on the area of the net mouth; e.g., a net with a $0.2 \mathrm{~m}^{2}$ mouth area towed from bottom to surface would collect the plankton under $0.2 \mathrm{~m}^{2}$ of lake surface.

\section{Biomass Determination}

To determine the mean individual biomass of a zooplankton species, individuals were sorted from a sample under a dissecting microscope, blotted, dried under vacuum desiccation, and weighed on a calibrated quartz helix. From 5 to 200 dry individuals were weighed at a time to get an adequate deflection of the helix. To avoid bias in unconscious1y selecting only the larger individuals, several drops of plankton sample were placed on a watch glass and all individuals of a species were removed for drying. The total individuals weighed of any species were taken from several samples in case a species might average larger in some samples than in others. Due to the small size and relative scarcity of planktonic rotifers in these lakes, only the biomass of the most abundant species, Keratella americana, could be determined. For conversion of population estimates to biomass, all other rotifers were considered to be the same size as $\mathrm{K}$. americana. The obvious error involved is quite small in terms of total zooplankton biomass since $\underline{\mathrm{K}}$. americana, when most abundant, comprised only ca, 7 percent of the total biomass.

After the mean dry weight/individual of a species had been determined, the species biomass for any sample date was calculated by 
multiplying individuals $/ \mathrm{m}^{2}$ by $\mathrm{mg} /$ individual. The species biomasses were summed to obtain total zooplankton biomass.

\section{Secondary Production}

An estimate of yearly production was made for each zooplankton species except that rotifers other than $\underline{K}$. americana were lumped. In order to put limits on secondary production, three calculations were made: a minimum estimate, a maximum estimate, and a "best estimate." The minimum estimate for a species was obtained by summing the net positive change in population size over a year, then multiplying by the average mass per individual of the species. The other two estimates were unrelated to the minimum estimate, except that all were based on the same population data and biomass data.

The classical sigmoid growth curve for a population is described by the equation $\frac{\mathrm{dN}}{\mathrm{dt}}=\mathrm{rN}\left(\frac{\mathrm{K}-\mathrm{N}}{\mathrm{K}}\right) \quad$ where:

$$
\begin{aligned}
& N=\text { No. of individuals } \\
& t=\text { time } \\
& r=\text { instantaneous rate of increase } \\
& K=\text { carrying capacity of the environment }
\end{aligned}
$$

If $\mathrm{N}$ is very small relative to $\mathrm{K}$ the expression $\frac{\mathrm{K}-\mathrm{N}}{\mathrm{K}}$ simplifies to 1.0 and the resulting equation, $\frac{\mathrm{dN}}{\mathrm{dt}}=\mathrm{rN}$ describes the logarithmic phase of the growth curve. In this study $\mathrm{N}$ was considered to be very much smaller than $\mathrm{K}$ for several reasons :

1. The relative density of zooplankton in oligotrophic lakes such as those studied is very low. For example, maximum cladoceran densities in Anderson-Cue and McCloud are in the order of 50-100/11ter. Ward 
(1940) reported up to 2,000 cladocera/1 in a 8 mal1 pond and Borecky (1956) reported 3,500 cladocera/1 in Pymatuning Reservoir.

2. Density dependent effects on laboratory populations of Daphnia were not seen by Frank, et al. (1957) until densities of $1,000-2,000 / 1$ were reached.

3. A plot of $\mathbf{r}$ vs. $\mathrm{N}$ for data from Anderson-Cue shows no tendency for $r$ to decline as $\mathrm{N}$ gets large (Figure 1). If $\mathrm{N}$ were approaching $\mathrm{K}, \mathrm{r}$ should be approaching zero.

The equation $\frac{d N}{d t}=r N$ can be written in its integrated form: $\mathrm{N}_{\mathrm{t}}=\mathrm{N}_{\mathrm{o}} \mathrm{e}^{\mathrm{rt}}$, and taking natura1 logarithms: $\ln \mathrm{N}_{\mathrm{t}}=\mathrm{rt}+\ln \mathrm{N}_{\mathrm{o}}$, which, when $1 \mathrm{n} \mathrm{N}_{t}$ is plotted against $t$, gives a straight line with $r$ as the slope.

In this study logarithms of population were plotted against time and each slope was considered to be an estimate of $r$ over that time period. For any species the maximum positive slope observed was considered to approximate $r_{m}$, the intrinsic rate of increase for that species. To determine maximum production, each species was considered to be reproducing at $r_{m}$ at all times during the year so that observed differences between $r$ and $r_{m}$ were considered to be due entirely to a variable death rate. The maximum productivity at any time was calculated from the equation, $\quad P_{m}=\mathrm{N}_{\mathrm{t}} \mathrm{r}_{\mathrm{m}} \mathrm{B}$, where:

$P_{\mathrm{m}}=$ maximum productivity

$\mathrm{N}_{\mathrm{t}}=$ population size at time $\mathrm{t}$

$r_{m}=$ maximum observed instantaneous rate of increase

$B=$ average biomass per individual. 


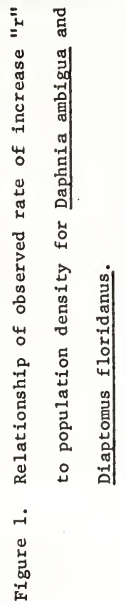




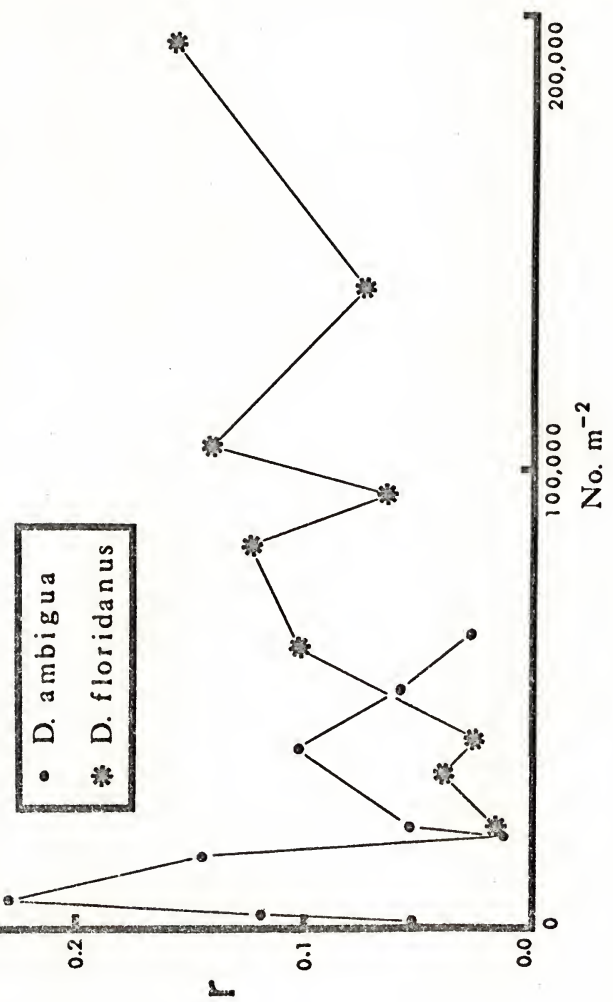


Values of $P_{m}$ were integrated over a year's time to get maximum yearly production.

The "best estimate" of production was determined similarly to maximum production except that all positive $r$ values were used to determine productivity: $\quad P=\mathrm{N}_{\mathrm{t}} \mathrm{r}_{\mathrm{t}} \mathrm{B}$.

$\mathrm{N}_{t}$ and $\mathrm{B}$ are the same as above.

$r_{t}=$ the observed rate of increase at time $t$.

$\rho=$ productivity .

Productivity was integrated over time to get a "best estimate" for yearly production. Finally production values for all species were summed to get total zooplankton production.

\section{Predation}

Labidesthes sicculus was considered to be the chief zooplankton predator in these lakes. The population size of L. sicculus was estimated using the Peterson mark-recapture method as described by Ricker (1958). Fish were captured individually at night with dipnets and each fish was immediately marked by clipping a pectoral fin and released. Since L. sicculus will lie at the surface in shallow water on a dark night, the marking procedure was fairly simple. The brief period of handling ensured minimum damage to the fish. Recaptures were made after one week.

At numerous times during the year, samples of $\mathrm{L}$. sicculus we re collected with a dipnet or seine and preserved in 10 percent formalin for later analysis. To determine food habits, each fish was measured and its gut contents analyzed. The entire gut was removed, carefully 
pulled apart, and washed with a few drops of water in a Sedgewick-Rafter counting chamber. All recognizable organisms in the gut were counted under $21 \mathrm{x}$ magnification with frequent use of higher magnification to check identification. The counts of zooplankton in the gut were converted to total mass of zooplankton eaten by multiplying the number of each species by the mean individual biomass for the species.

\section{$\underline{\text { Statistics }}$}

Statistical tests were used to evaluate apparent trends in the results. Since sampling frequency was arbitrarily chosen, samples were considered to be random with respect to population size or biomass. Total biomass values were assumed to have an approximately normal distribution. In determining correlation coefficients between species, only samples in which both species occurred were used, as inclusion of zero values would constitute a significant departure from a normal distribution and thus invalidate the test statistic "r." All statistical tests used are described by Mendenhall (1967). A significance level of 0.05 was used throughout. 


\section{RESULTS}

\section{Population Density}

The densities (No. $/ \mathrm{m}^{2}$ ) of zooplankton species are shown in Tables 2-9. Species of which only one or two individuals were seen during the study are not included since their contribution to the biomass of zooplankton is negligible. Most of such occasional sightings represent strays from the littoral zone. Sample dates where a species was not seen are indicated by dashes in the tables.

\section{Blomass}

Table 10 shows the mean (with 95 percent confidence interval) individual biomass of the common zooplankton species. These values represent average dry weights for individuals of each species. The scarcity of Holopedium amazonicum in these lakes is reflected in the few individuals obtained for weighing and the consequent inaccuracy of weight determination for this species. The total zooplankton biomass is shown in Figures 2-4; and the blomasses of copepods, cladocera, and rotifers are shown in Figures 5, 6, and 7, respectively. 


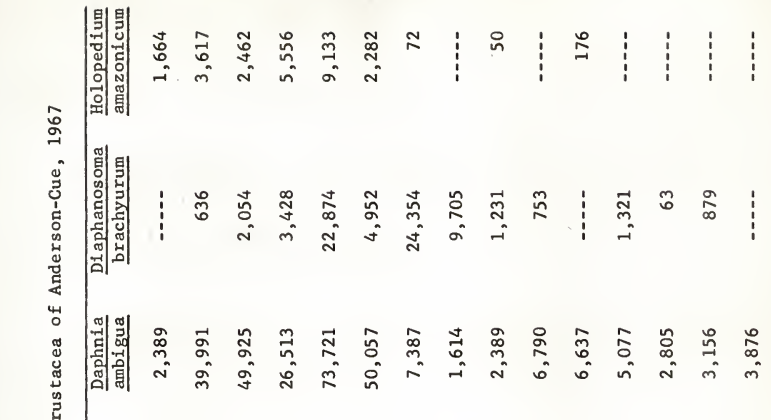

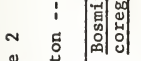

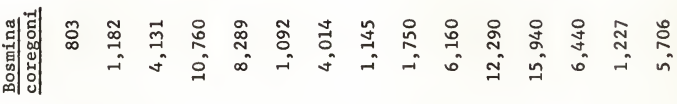

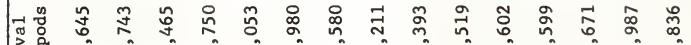

$$
\begin{aligned}
& \text { 营高 } \\
& \text { ก } \\
& \text { กิ } \\
& \text { 完 } \\
& \text { a }
\end{aligned}
$$

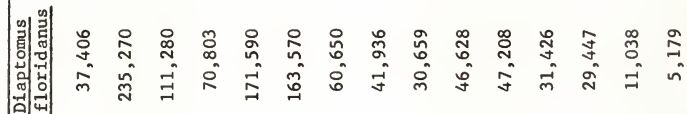

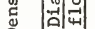

$$
\begin{aligned}
& \text { 동 }
\end{aligned}
$$

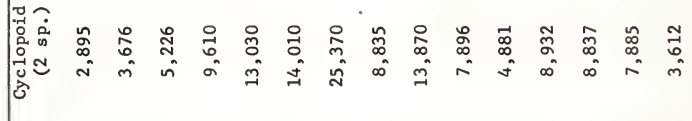

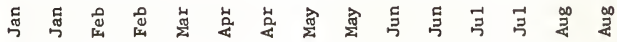

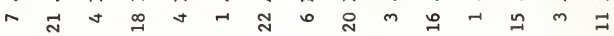


๙ู

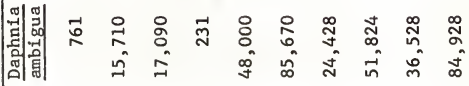

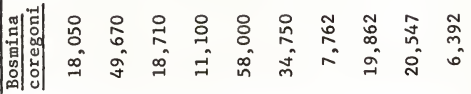

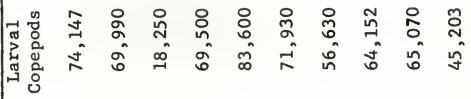

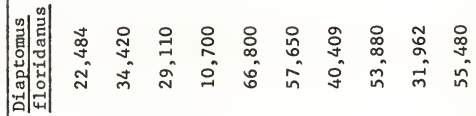

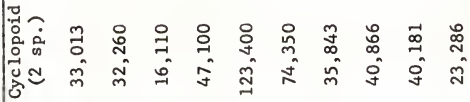

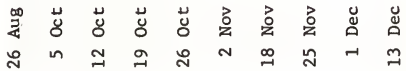




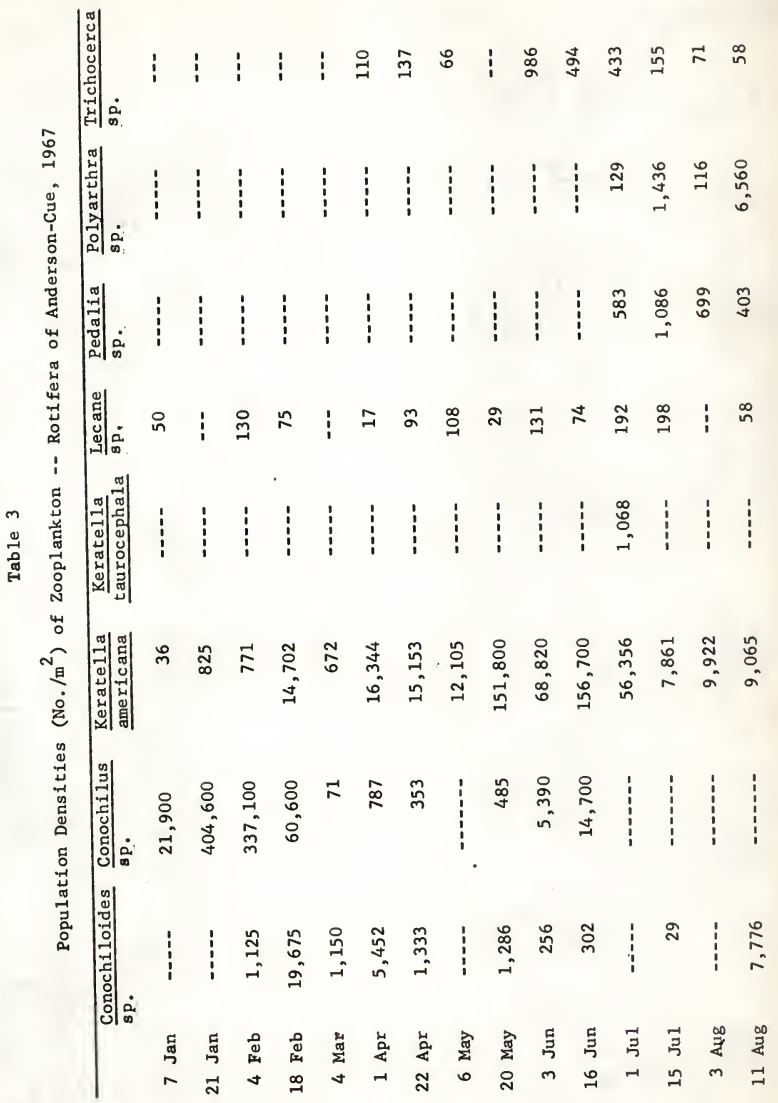




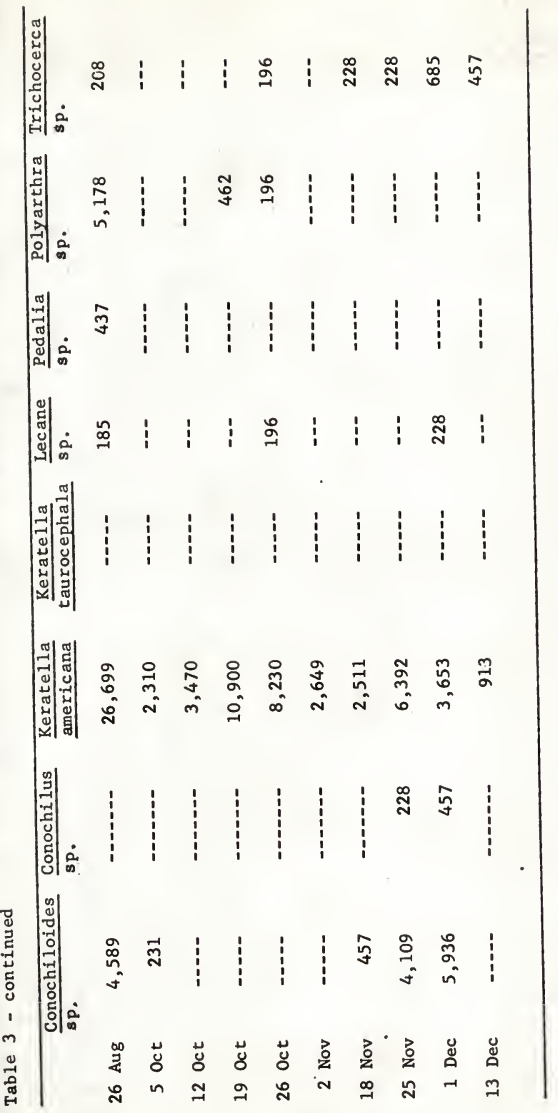




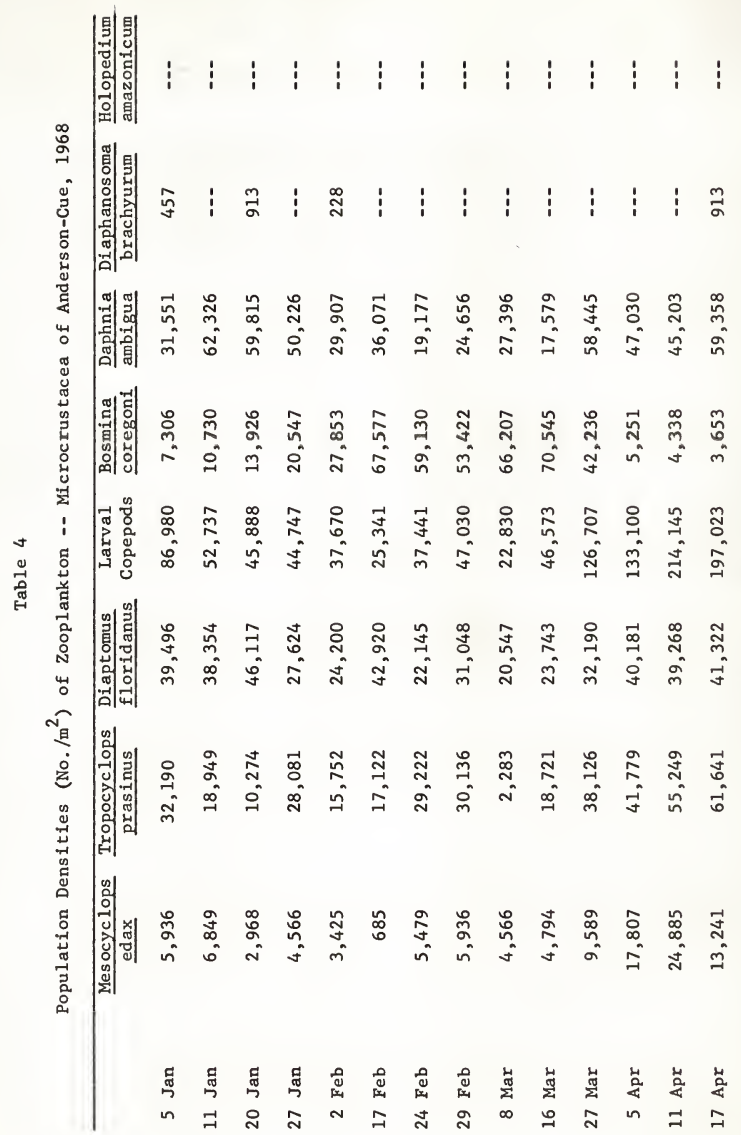




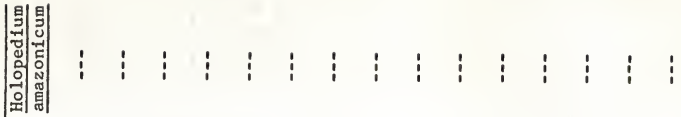

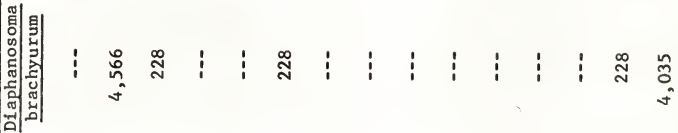

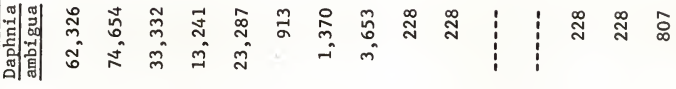

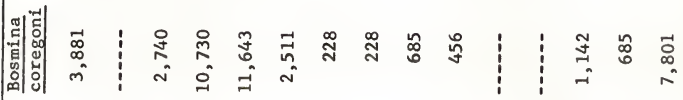

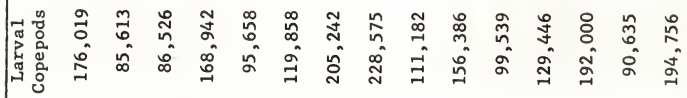

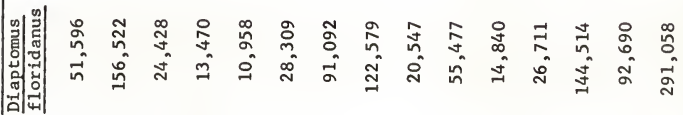

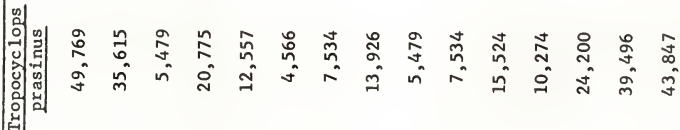

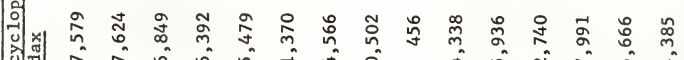

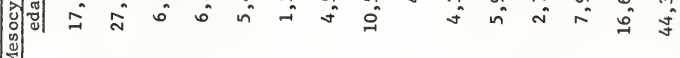

$$
\begin{aligned}
& \text { iा }
\end{aligned}
$$

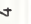

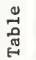

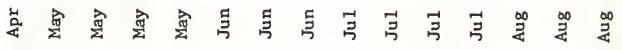

$$
\begin{aligned}
& \text { ก } \ \text { ก }
\end{aligned}
$$




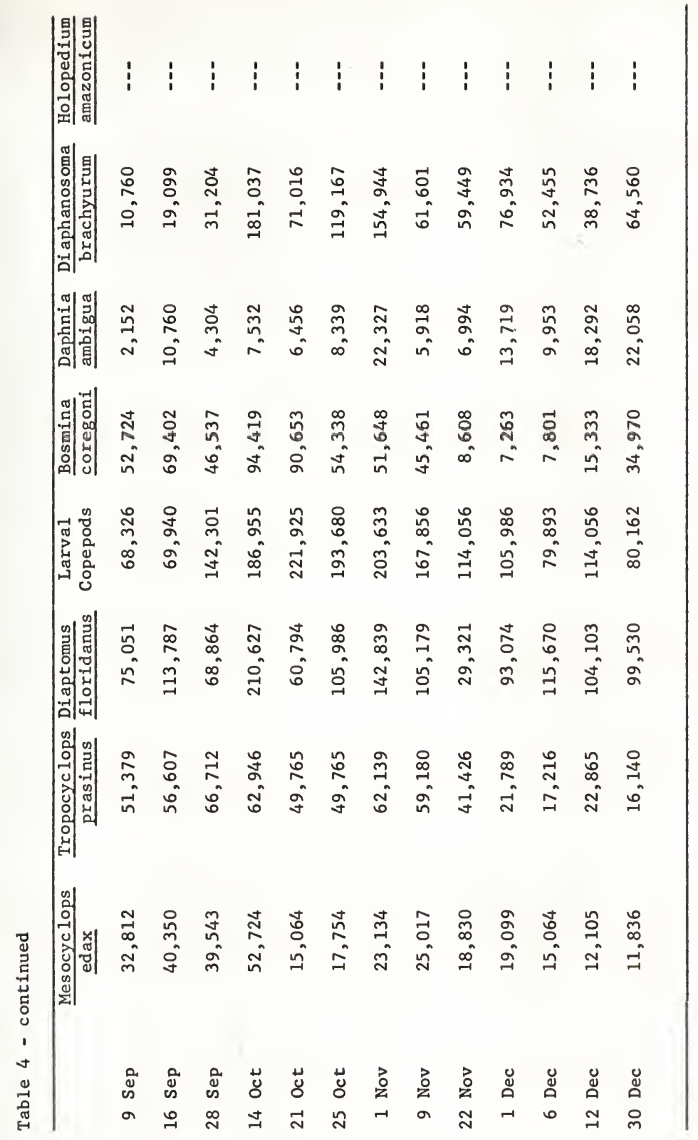




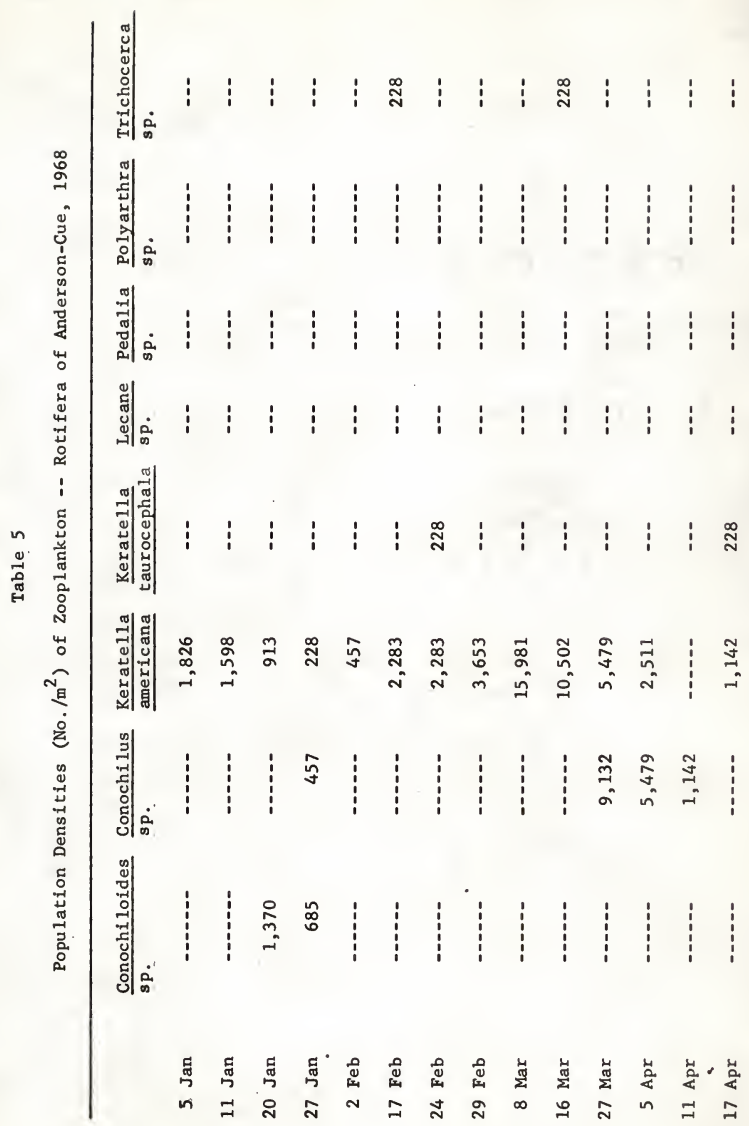




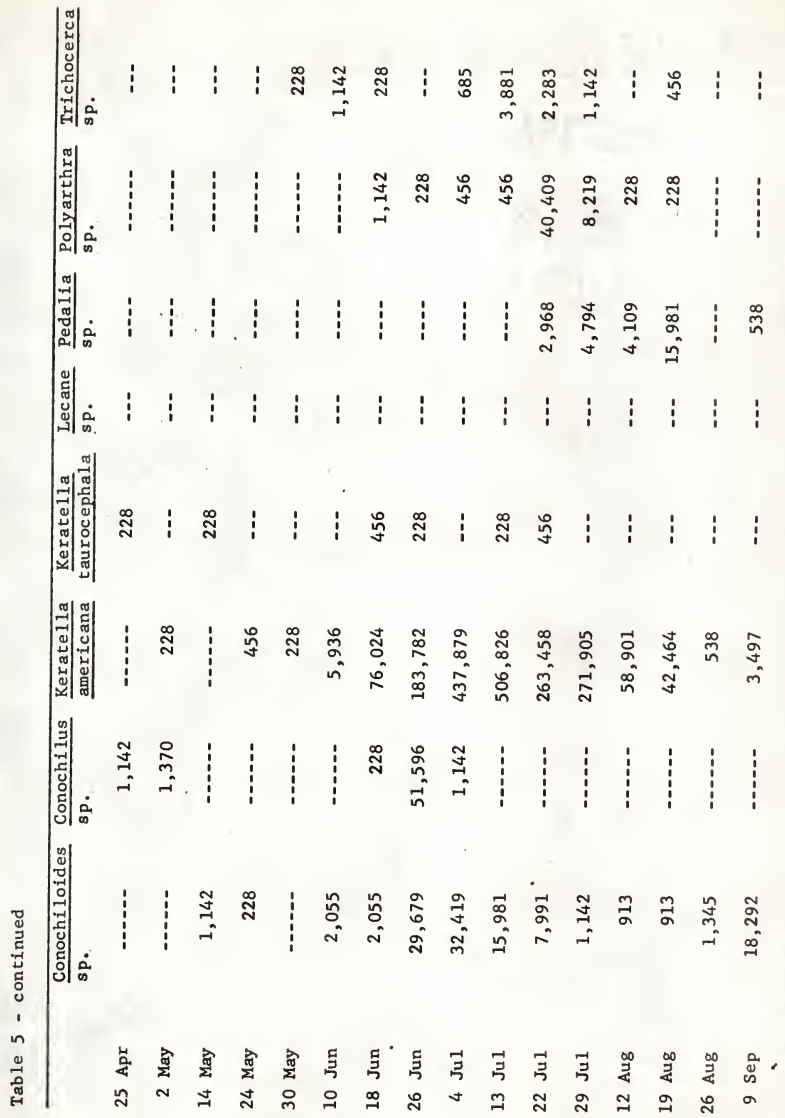




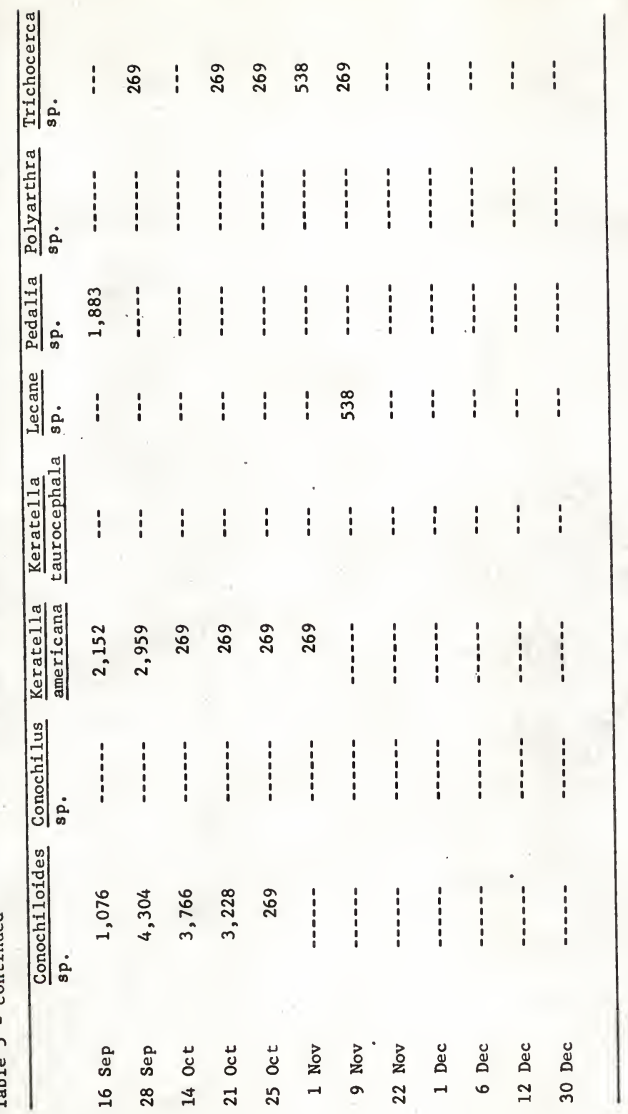




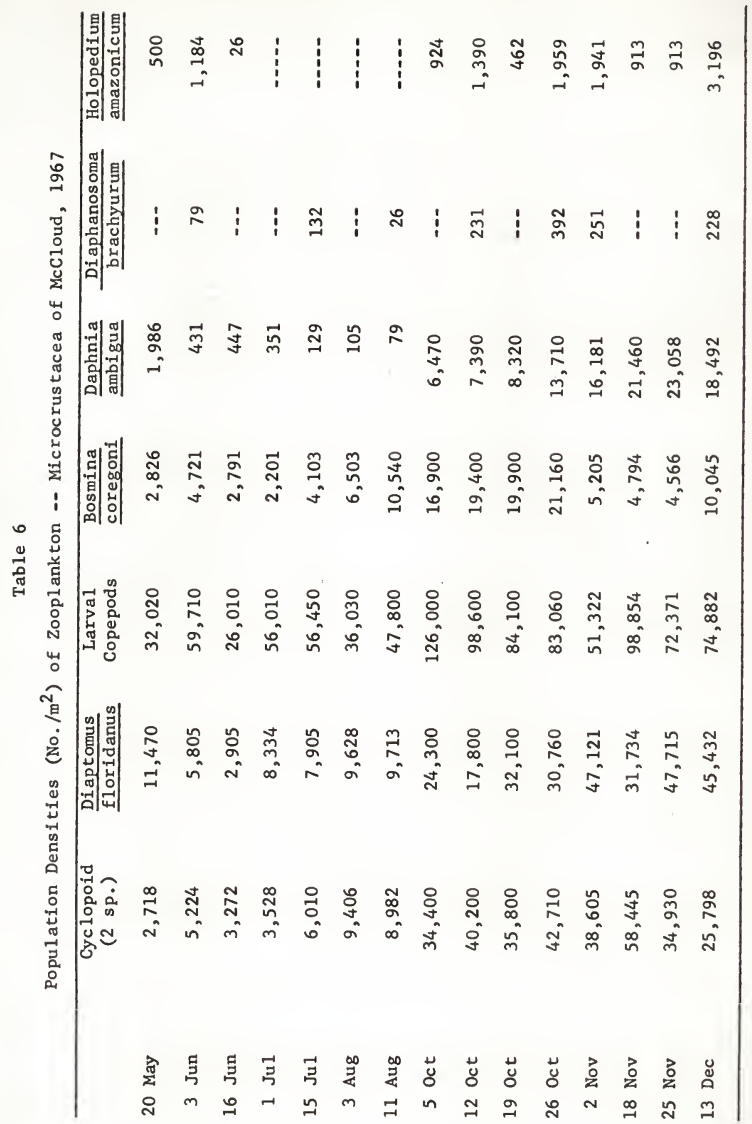




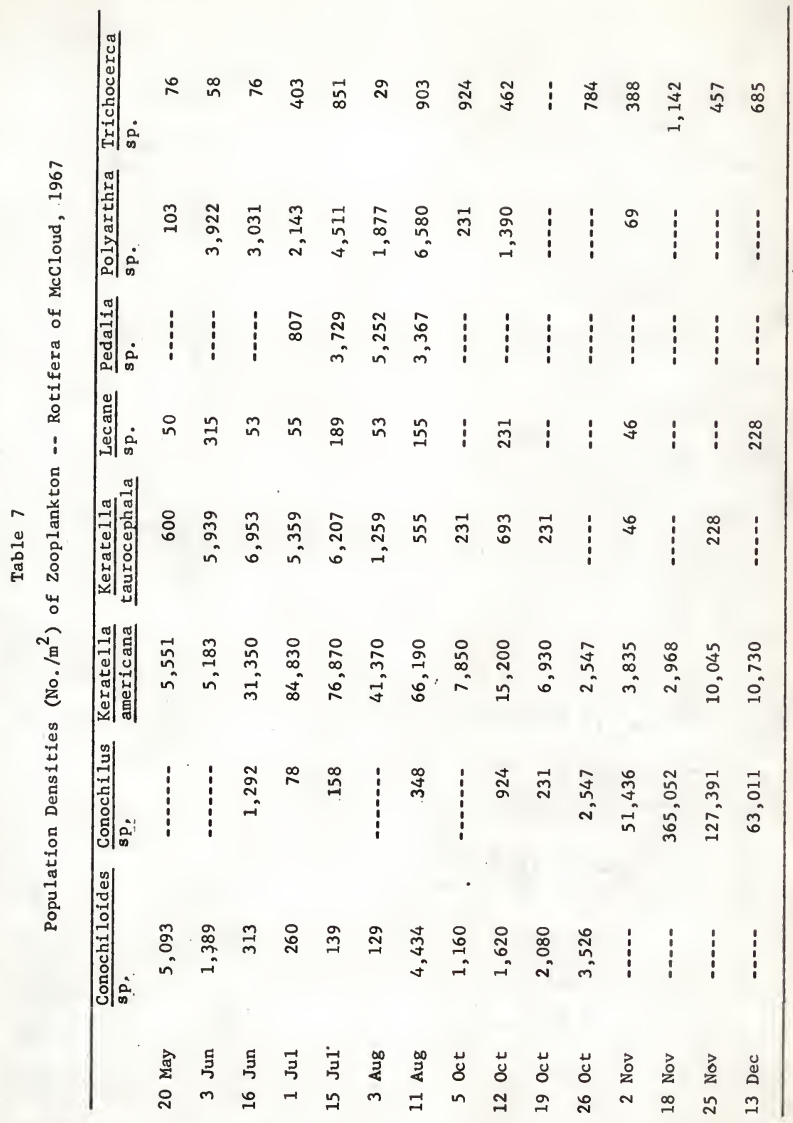




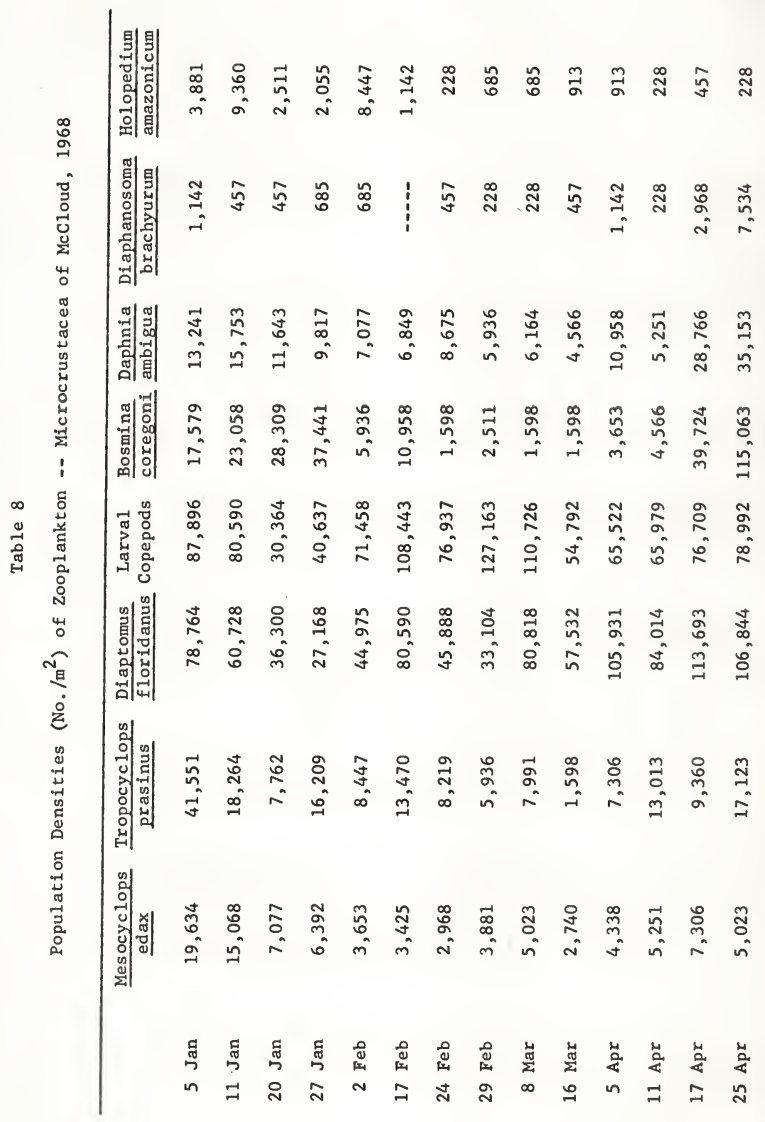




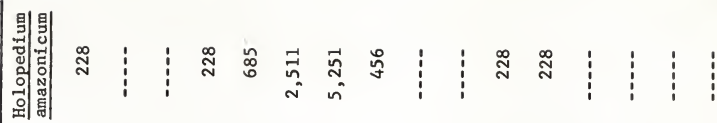

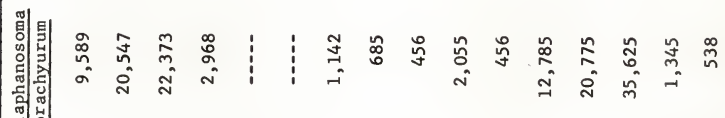

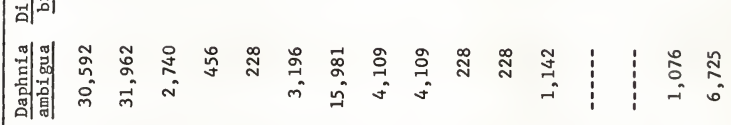

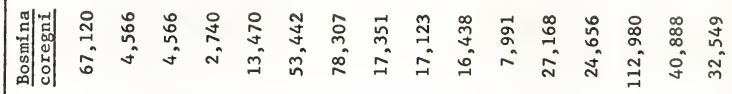

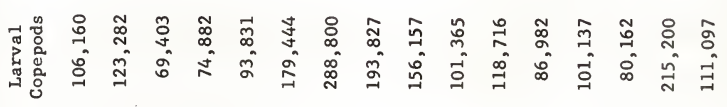

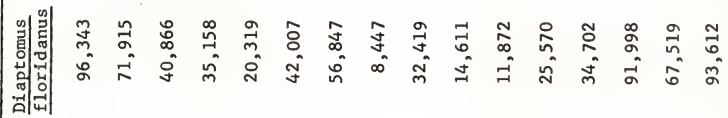

$$
\begin{aligned}
& \text { 苟柔 }
\end{aligned}
$$

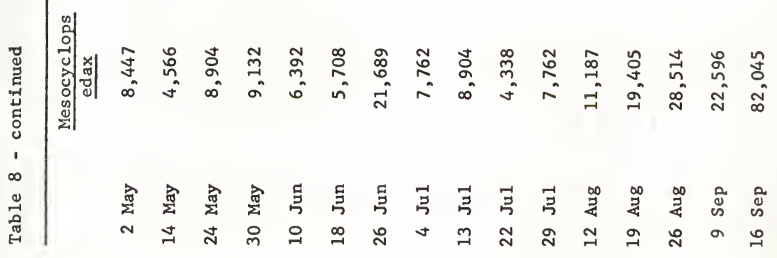




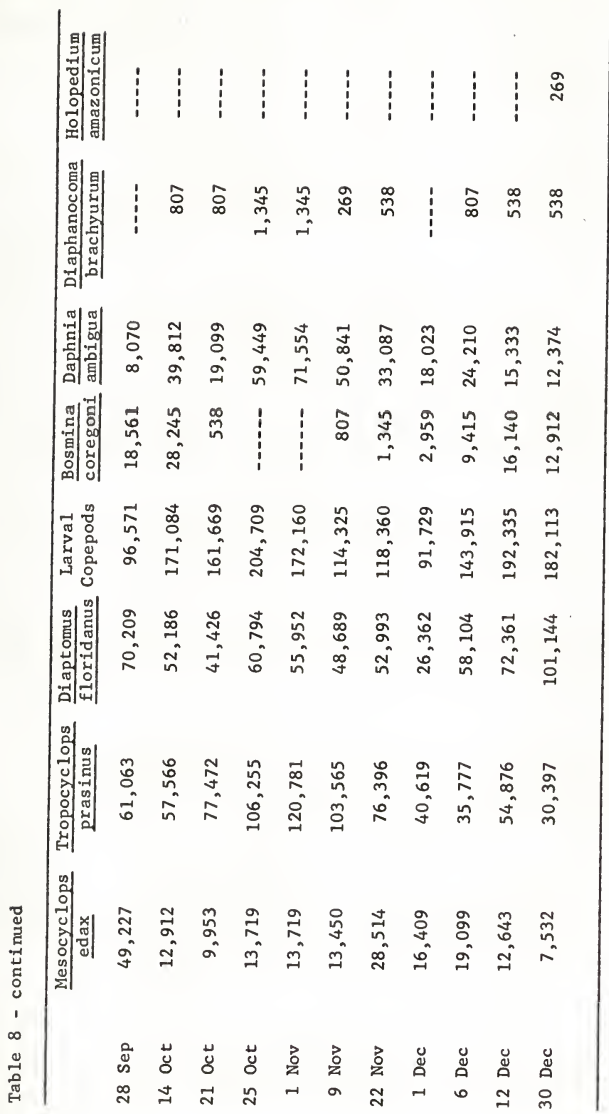




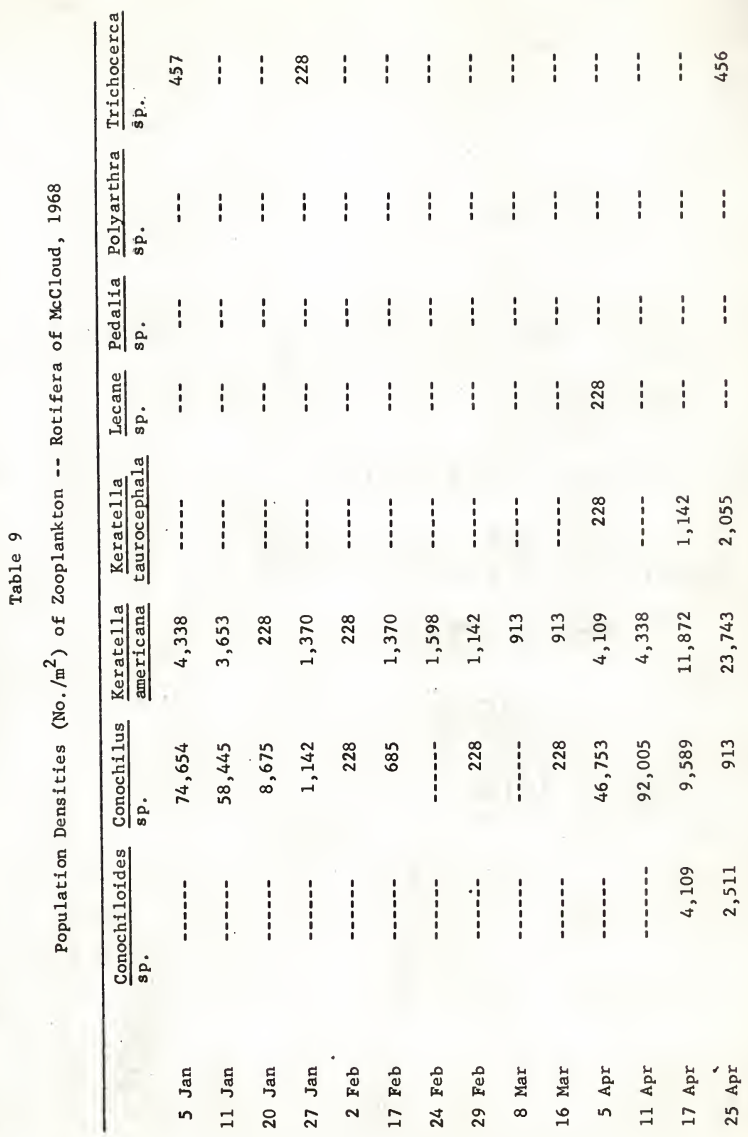




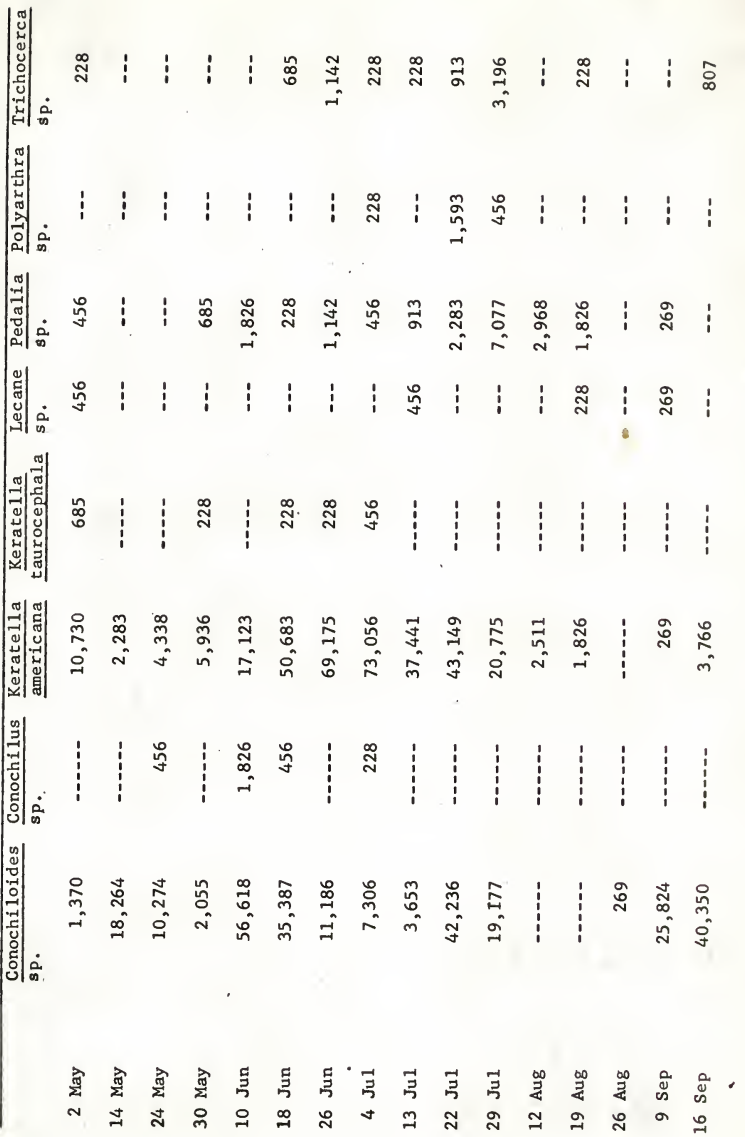




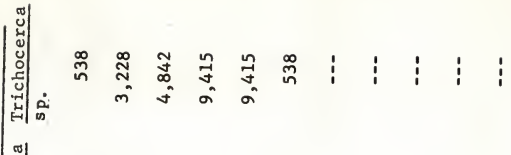

$$
\begin{aligned}
& \text { i }
\end{aligned}
$$

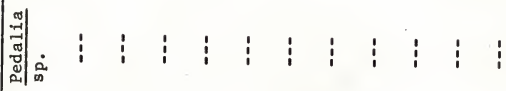

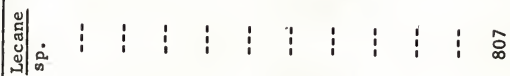

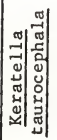

$$
\begin{aligned}
& \text { (1) }
\end{aligned}
$$

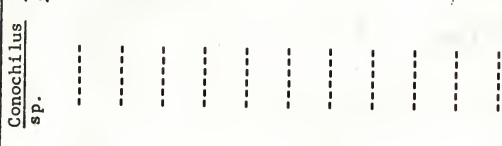

$$
\begin{aligned}
& \text { (1) } \\
& \text { 导 } \\
& \text { 이요 }
\end{aligned}
$$

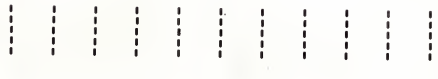




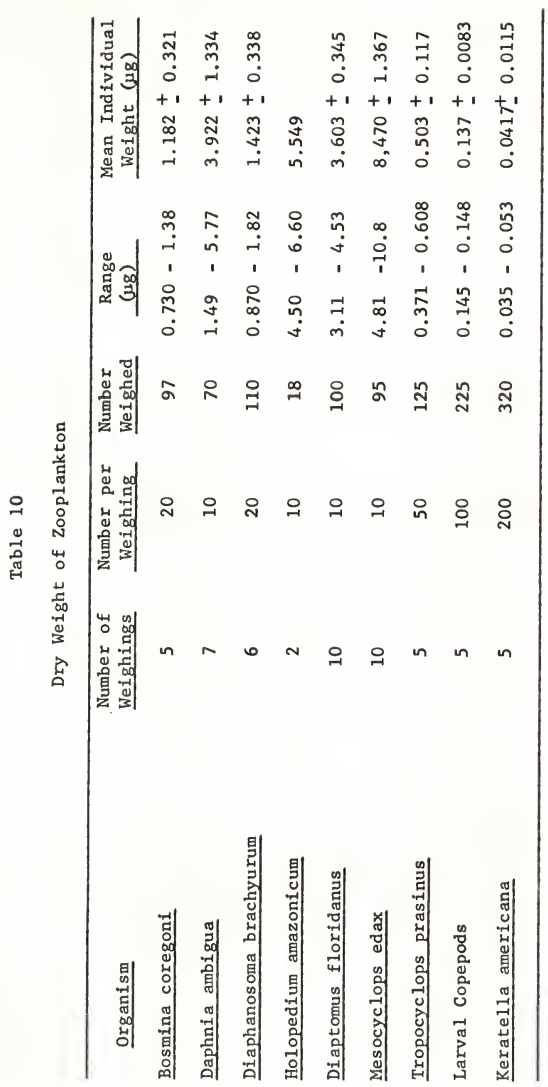


Changes in Lake Anderson-Cue

Enrichment of a lake may cause changes in the species present, with some dropping out perhaps being replaced by new species. The tendency for a species to become more or less common should be reflected in changes in the fraction of samples in which it was found. To test the significance of changes in frequency, the fraction of samples was treated as a binomial variable "p" and the difference between $\mathrm{P}_{1967}$ and $\mathrm{P}_{1968}$ was tested using a " $\mathrm{z}$ " test and pooled estimate of variance, where

$$
\begin{aligned}
& z=\frac{p_{1}-p_{2}}{p_{1}+p_{2}} \text { and } \sigma p_{1}+p_{2} \\
& \sqrt{\frac{p^{*}\left(1-p^{*}\right)}{n_{1}}+\frac{p^{*}\left(1-p^{*}\right)}{n_{2}}} \quad \text { is estimated by }
\end{aligned}
$$

$\mathrm{p}^{*}$ is the best estimate of $\mathrm{p}$ over both periods, i.e., the combined estimate of both. Table 11 shows the values of $p$ and the associated $z$ for species falling in the range $0.2<p<1.0$. Rarer species $(p<0.2)$ were excluded since the test used could not show significant differences with the number of samples available.

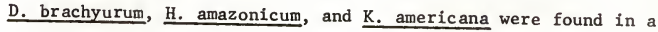
significantly different fraction of the samples from Anderson-Cue in 1967 and 1968, Anderson-Cue, 1968, and McCloud,. 1968, but not from Anderson-Cue, 1967, and McCloud, 1968. Conochilus sp. was found in a different fraction of the samples in Anderson-Cue, 1967, and 1968, but not in other lake-year combinations. 


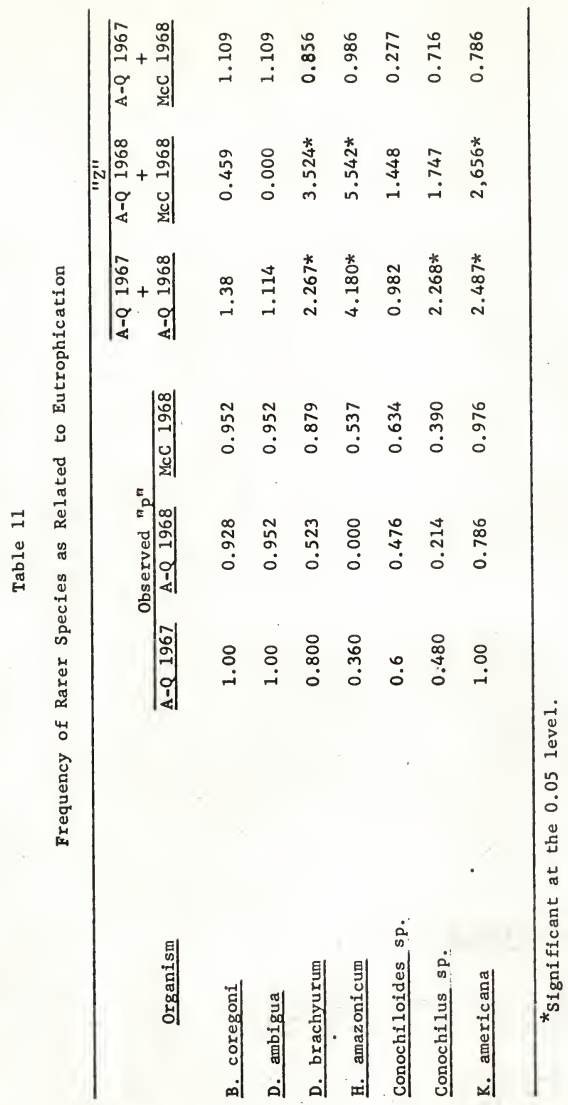


The mean biomass (and 95 percent confidence interval) for each species in different lake-years is shown in Table 12. These means were tested for each combination of lake-years. Most species did not differ significantly between lakes or years. The mean biomass of D. brachyurum differed significantly in Anderson-Cue between 1967 and 1968, and between Anderson-Cue, 1968, and McCloud, 1968, but not between AndersonCue, 1967, and McCloud, 1968. The mean biomass of B. coregon 1 differed between 1967 and 1968 in Anderson-Cue, but nefther year in Anderson-Cue differed from McCloud, 1968. The apparent increase in mean total biomass from 1967 to 1968 in Anderson-Cue is not statistically significant at the 0.05 level, nor is the value for McCloud, 1968, statistically different from either year in Anderson-Cue.

\section{General Population Dynamics}

Climatic factors affecting zooplankton populations would be expected to act on both lakes in the same manner. To determine the extent to which species in both lakes varied in the same fashion, correlation coefficients between lakes were calculated for the biomass of each species and group of zooplankton in 1968. (Table 13). The results show total biomass to be strongly correlated between lakes. The correlation coefficient for the total biomass in the two lakes for the period of May to December, 1967, was found to be 0.749 , showing that the tendency toward similarity in the two lakes was approximately equal in both years.

All group correlations between the two lakes are significant, usually being much better than correlations for component species. 


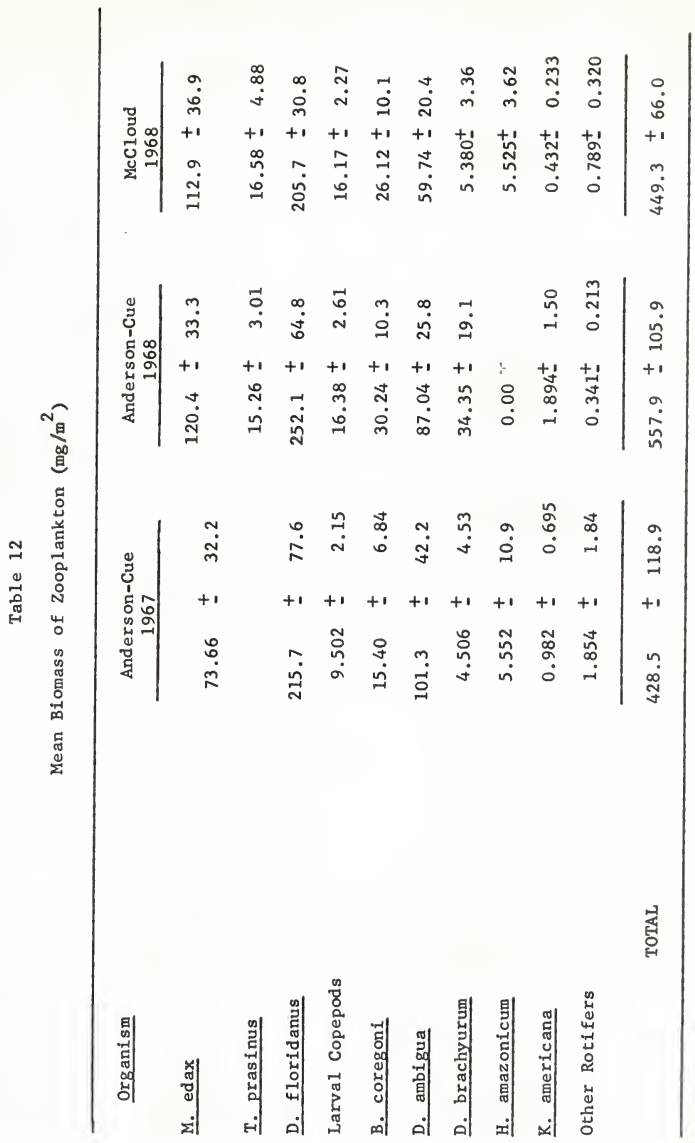


Table 13

Relative Stability of Populations

\begin{tabular}{|c|c|c|c|}
\hline & $\begin{array}{c}\text { Coefficient } \\
\mathrm{A}-\mathrm{Q} \\
\end{array}$ & $\begin{array}{l}\text { of Variation } \\
\mathrm{McC} \\
\end{array}$ & r Value \\
\hline Tota1 Zooplankton & 62.0 & 48.0 & $0.686 *$ \\
\hline Copepoda & 75.7 & 51.4 & $0.552 *$ \\
\hline Cladocera & 69.7 & 77.0 & $0.523 *$ \\
\hline Rotifera & & & $0.413 *$ \\
\hline M. edax & 90.5 & 106.9 & $0.605 *$ \\
\hline T, prasinus & 64.4 & 96.0 & $0.605 *$ \\
\hline D. floridanus & 84.0 & 49.0 & 0.252 \\
\hline Larval Copepods & 52.1 & 45.9 & 0.346 \\
\hline B. coregoni & 111.4 & 126.6 & -0.262 \\
\hline D. ambigua & 96.7 & 111.7 & 0.101 \\
\hline D. brachyurum & 181.5 & 204.3 & -0.366 \\
\hline H. amazonicum & $\cdots$ & 210.2 & -- \\
\hline K. americana & 257.9 & 176.3 & $0.764 \%$ \\
\hline Other Rotifers & 204.2 & 132.7 & 0.029 \\
\hline
\end{tabular}

*Significant at the 0.05 level. 
The only species showing a better correlation than its group or the

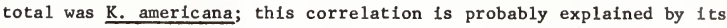
seasonal nature.

Coefficients of variation for major species and groups in the two lakes are also shown in Table 13. The coefficient of variation is defined as $\frac{\text { standard deviation X } 100}{\text { mean }}$. In general, the individual species are much more variable than the total. The Cladocera and Rotifera, particularly, are less variable as a group than as individual species. Larval copepods are less variable than adults of any spectes and less variable than the adults grouped together.

\section{Relationship of Temperature to Zooplankton}

Variations in surface temperature and total zooplankton blomass in the two lakes are shown in Figures 2-4. The biomass curves for Anderson-Cue and McCloud in 1968 follow the temperature curve closely until about May when biomass falls. Biomass remains low (with some oscillations) until late August or early September, then climbs rapidly to $i$ ts highest level from which it tends to decline following the fall temperature decrease. To check the apparent relationship of temperature and biomass, correlation coefficients were calculated (Table 14) using only data from that section of the year in which biomass appeared to follow temperature, 1.e., all dates except the period of 6 May through 26 August in A-Q 1967, 14 May through 19 August in A-Q 1968, and 2 May through 9 September in McC 1968.

Total zooplankton blomass and copepod biomass were significantly correlated with temperature during the nonsummer months in both Anderson-Cue and McCloud in 1968. Rotifer blomass (including the summer 


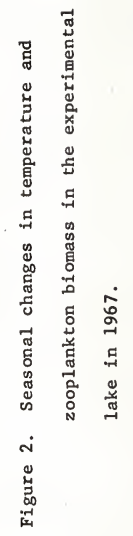




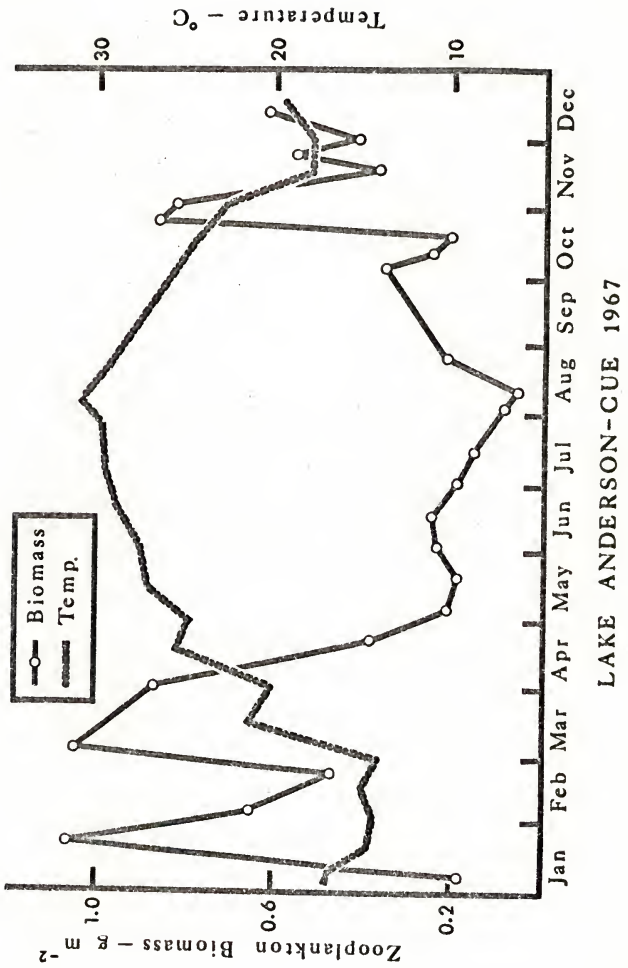




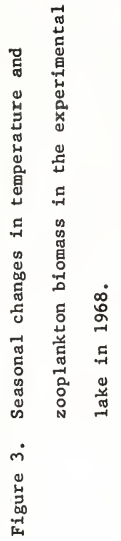




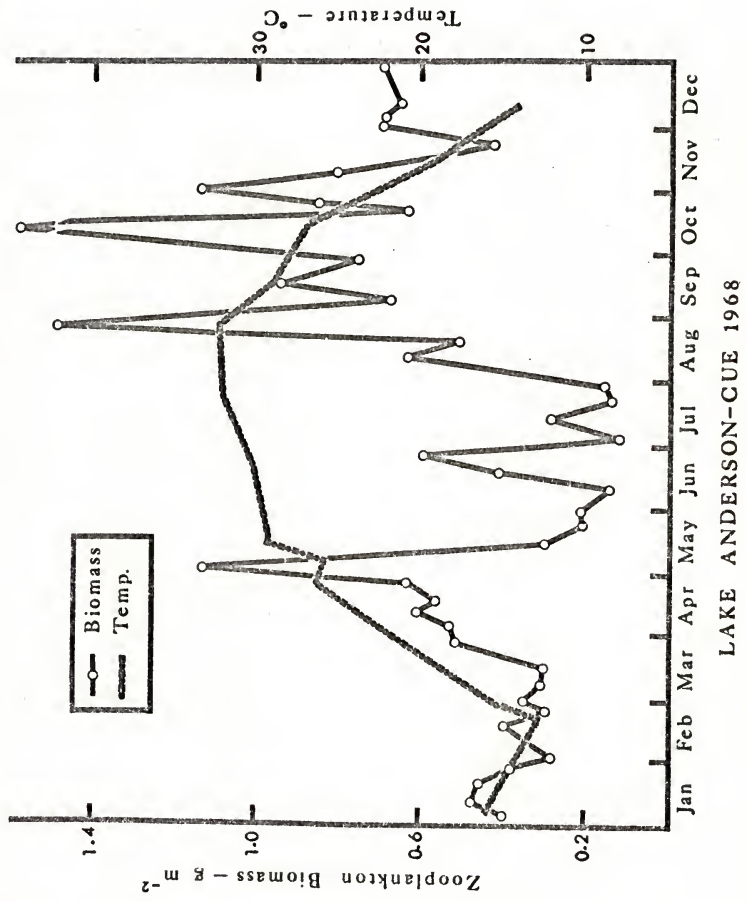




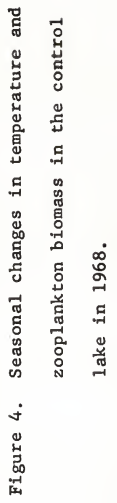




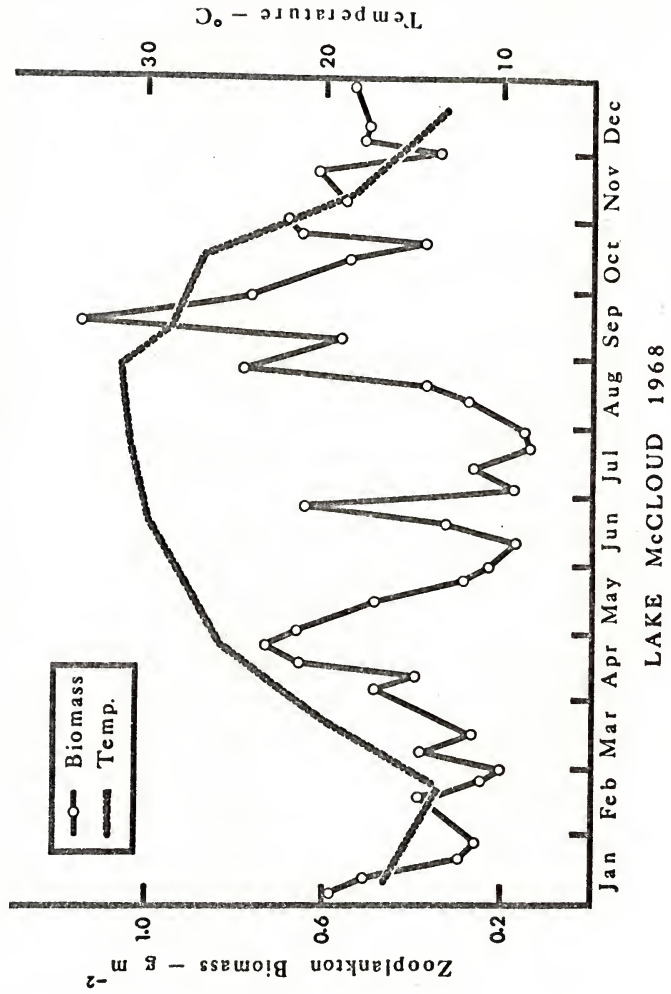


Table 14

Relationship between Temperature and Zooplankton Biomass (r values)

\begin{tabular}{|c|c|c|c|}
\hline Group & $\begin{array}{c}\text { Anderson-Cue } \\
1967 \\
\end{array}$ & $\begin{array}{c}\text { Anderson-Cue } \\
1968 \\
\end{array}$ & $\begin{array}{l}\text { McCloud } \\
1968 \\
\end{array}$ \\
\hline Total Zooplankton & -0.349 & $0.683 *$ & $0.674 *$ \\
\hline Copepods & -0.330 & $0.703 *$ & $0.609 *$ \\
\hline Cladocera & -0.237 & 0.003 & 0.332 \\
\hline Rotifers & 0.409 & $0.461 *$ & $0.437 *$ \\
\hline
\end{tabular}

data, as rotifers did not show a summer decline--Figure 7) was significantly correlated with temperature in 1968 in both lakes. No biomass to temperature correlations were significant for Anderson-Cue, 1967.

The phenomenon of a summer decline was confined to the copepods and cladocera (Figures 5-7). The rotifers, by contrast, reached their maximum biomass during the general sumer decline. To determine the nature of the summer decline, the difference between mean biomass in summer and nonsummer months was tested for total as well as individual species using a t test (Table 15). M. edax, D. floridanus, and D. ambigua declined during the summer in both lakes, significantly so in at least one. Rotifers in general increased, $\underline{K}$. americana markedly so. Other species were ambiguous on their summer response, showing either no significant change or changes in different directions in 
the two lakes.

Some of the rarer species appeared to be more common during the summer months when total zooplankton biomass was low. To check this, data from all lake-years were pooled with samples divided into two groups: those taken when the water temperature was greater than $25^{\circ} \mathrm{C}$, and those taken at less than $25^{\circ} \mathrm{C}$. The value of $25^{\circ} \mathrm{C}$ was arbitrarily chosen because approximately half of the samples were taken at lower temperatures and half at higher temperatures. The frequency of occurrence (fraction of samples in which a species was seen) was treated as a binomial variable w1 th probabil1ty " $\mathrm{p}$ " and the observed occurrence at warm temperatures was compared with occurrence at cold temperatures (Table 16). Several of the rarer rotifers were seen in a statistically greater fraction of the samples taken when water temperature was above $25^{\circ} \mathrm{C}$. None were statistically more common at low temperatures.

\section{Food Limitation}

The food of zooplankton is mostly algae (Gauld, 1950, 1951; Gibor, 1956; Davis, 1958). As algal biomass was not measured directly in this study, the concentration of chlorophyl1 in the water (Figure 8) was assumed to Indicate the algal standing crop. Blomasses of different groups of zooplankton were compared with chlorophy 11 concentrations at the sample dates and at several points prior to the sample dates. The correlation coefficients obtained are shown in Table 17. Rotifer biomass showed no significant correlation with chlorophy 11 concentration. The best correlation between cladocera and chlorophyll occurred when a six day lag was included. However, this correlation, while significantly different from zero at the 0.05 level, would 


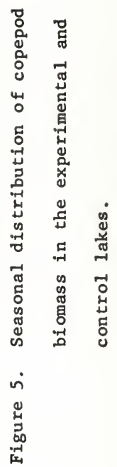




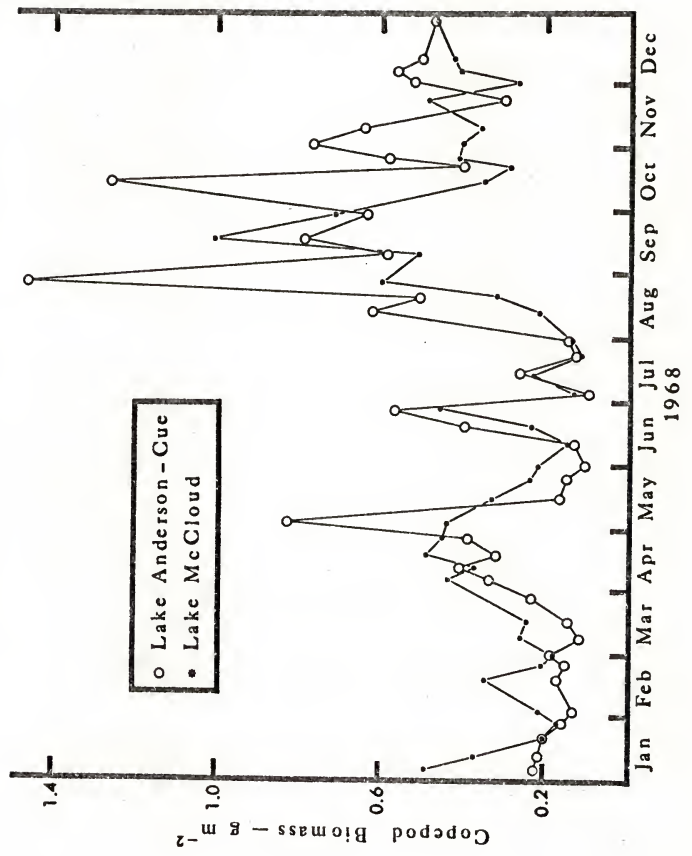




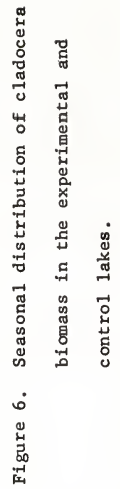




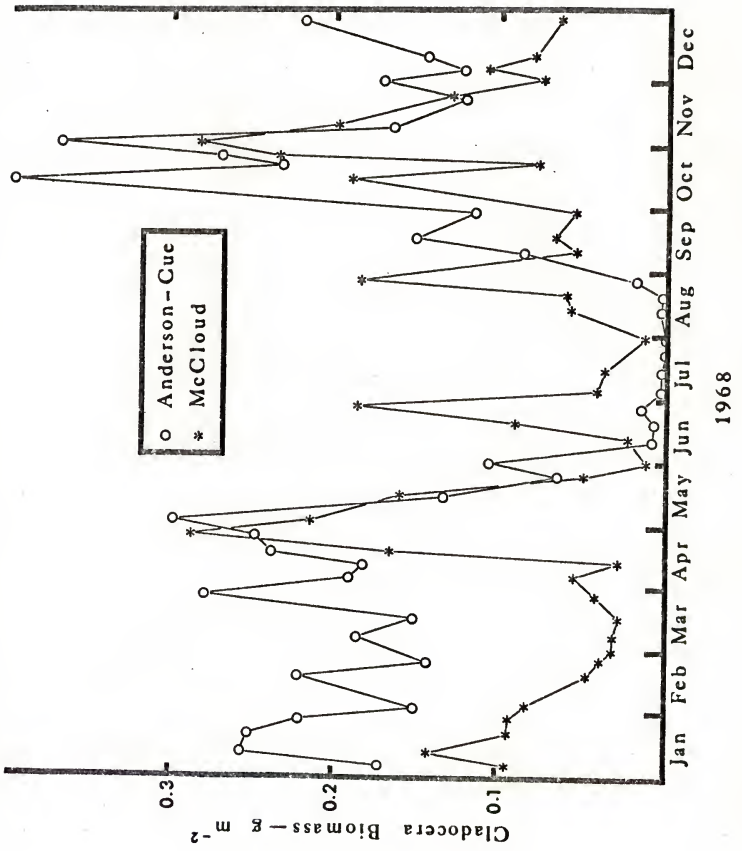


Figure 7. Seasonal distribution of rotifer blomass in the experimental and control lakes. 


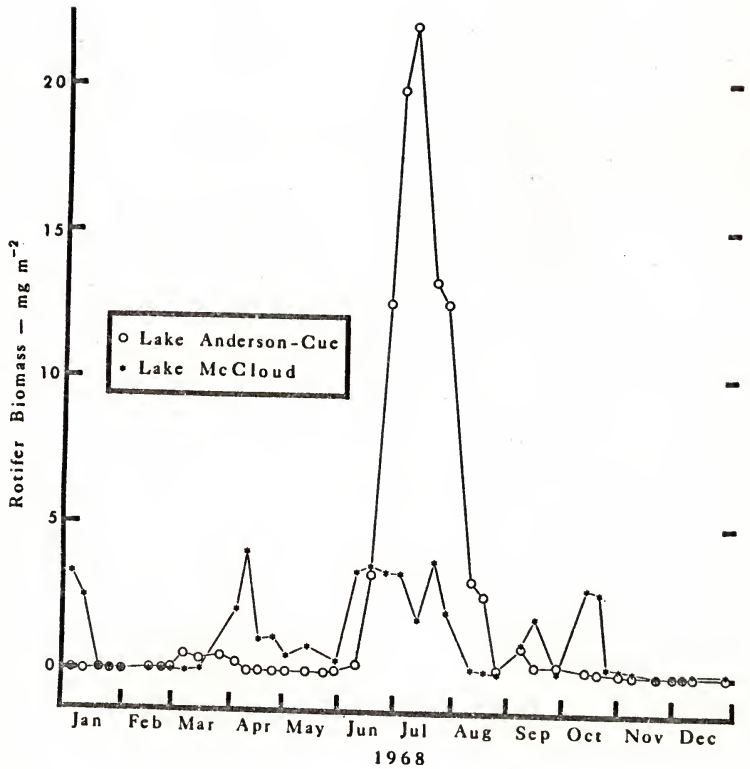




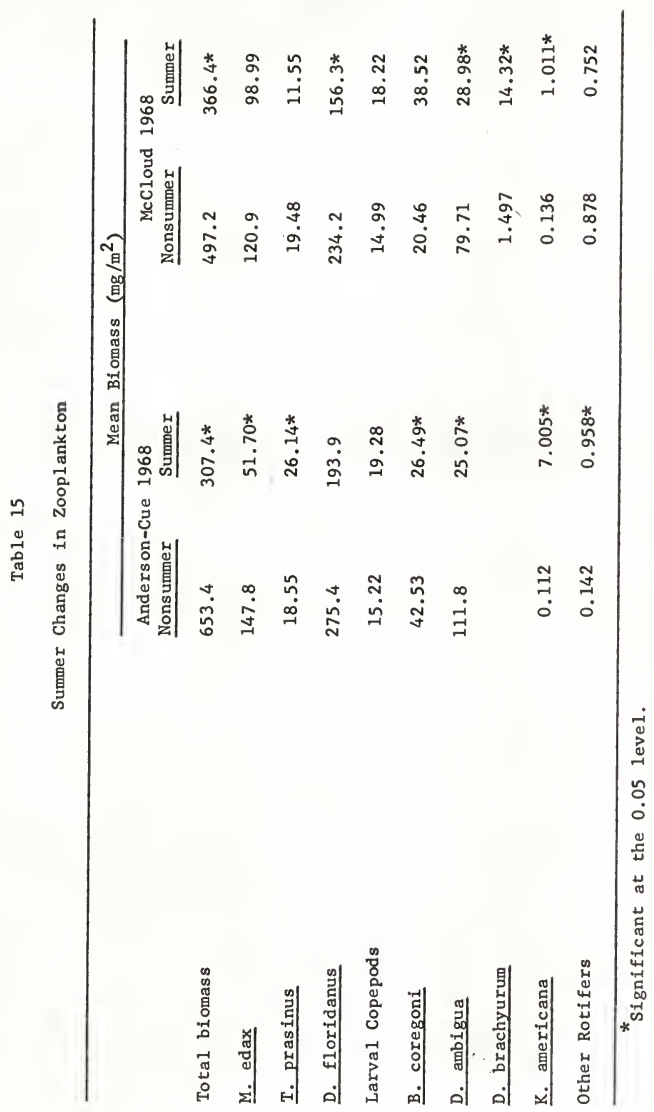




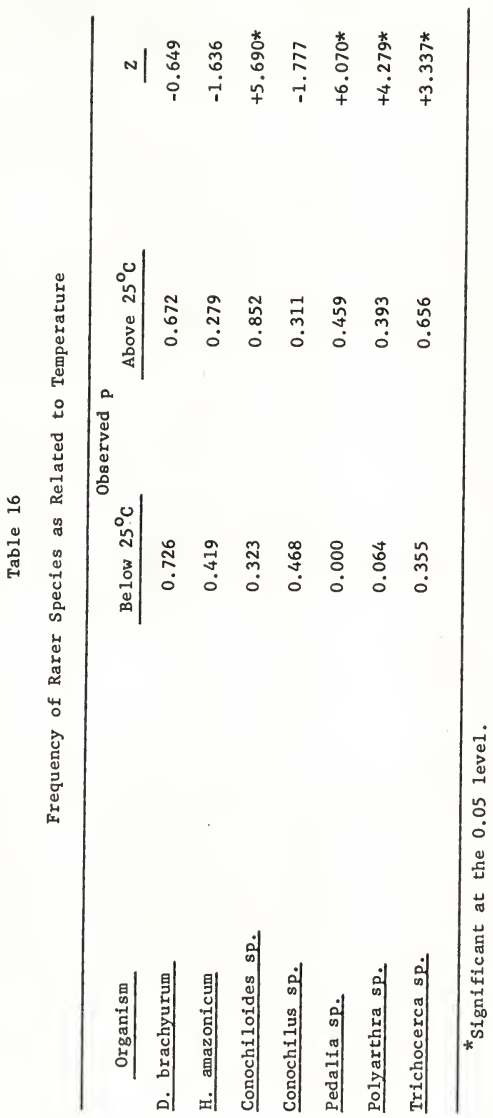


Figure 8. Annual variation of chlorophyl1 a In Anderson-Cue and $\mathrm{McCl}$ oud lakes. 

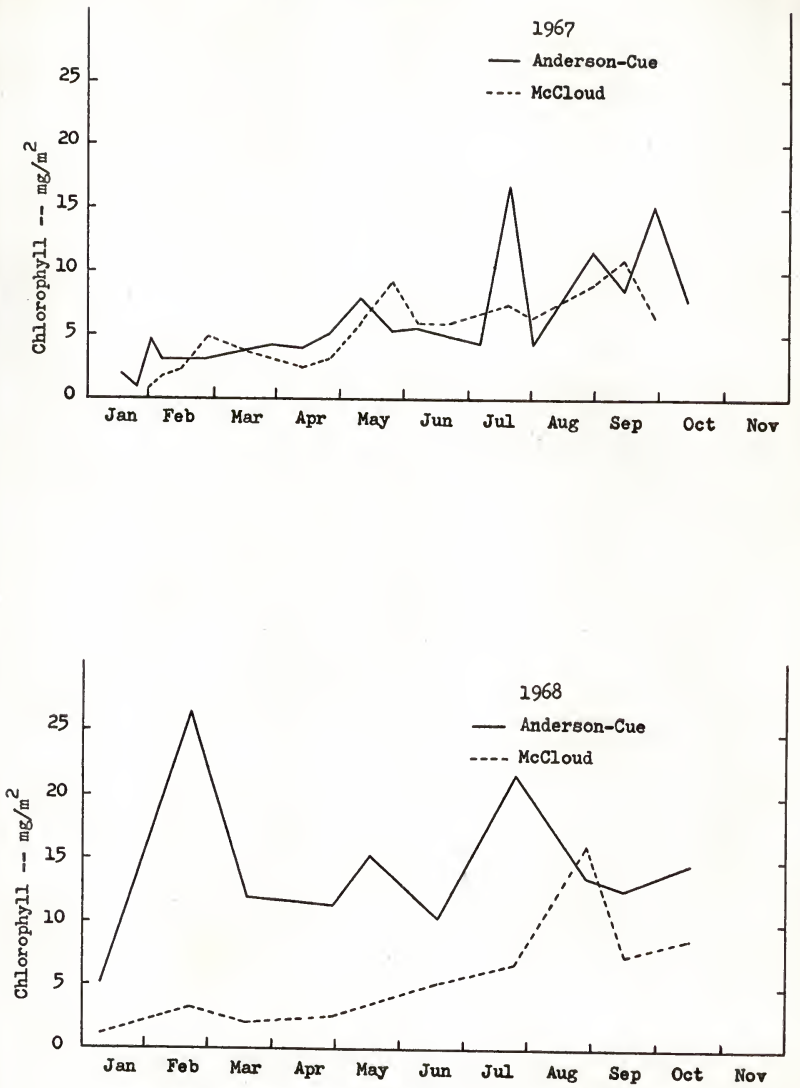
Table 17

Relationship between Zooplankton and Chlorophy 11

\begin{tabular}{|c|c|c|c|}
\hline Lag Period & $\begin{array}{l}\text { Rotifer } \\
\text { Biomass } \\
\end{array}$ & $\begin{array}{c}\text { Cladoceran } \\
\text { Blomass } \\
\end{array}$ & $\begin{array}{l}\text { Copepod } \\
\text { Biomass } \\
\end{array}$ \\
\hline 0 days & 0.172 & 0.207 & 0.065 \\
\hline 6 days & 0.129 & $0.280 *$ & 0.099 \\
\hline 15 days & 0.072 & 0.126 & 0.160 \\
\hline 21 days & 0.067 & 0.102 & $0.580 *$ \\
\hline 30 days & 0.076 & 0.131 & $0.313 *$ \\
\hline 40 days & 0.086 & 0.187 & $0.327 *$ \\
\hline
\end{tabular}

explain only about 8 percent of the variation in cladocera in terms of variations in chlorophy 11. Copepod biomass, on the other hand, is more strongly related to chlorophy 11 , but only after a lag period of 21 days or more.

Primary productivity (Figure 9) may give a better estimate of potential zooplankton food than does chlorophyll concentration. The correlations between zooplankton biomass and primary productivity are shown in Table 18. Mean monthly values of each were correlated to smooth out the extreme variations which occurred and to partly include variable lag periods which might be associated. Since zooplankton biomass declined in the summer and primary productivity did not, correlations were also calculated omitting the summer months. Considered for 


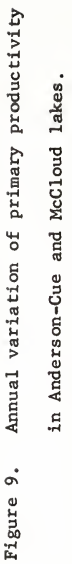




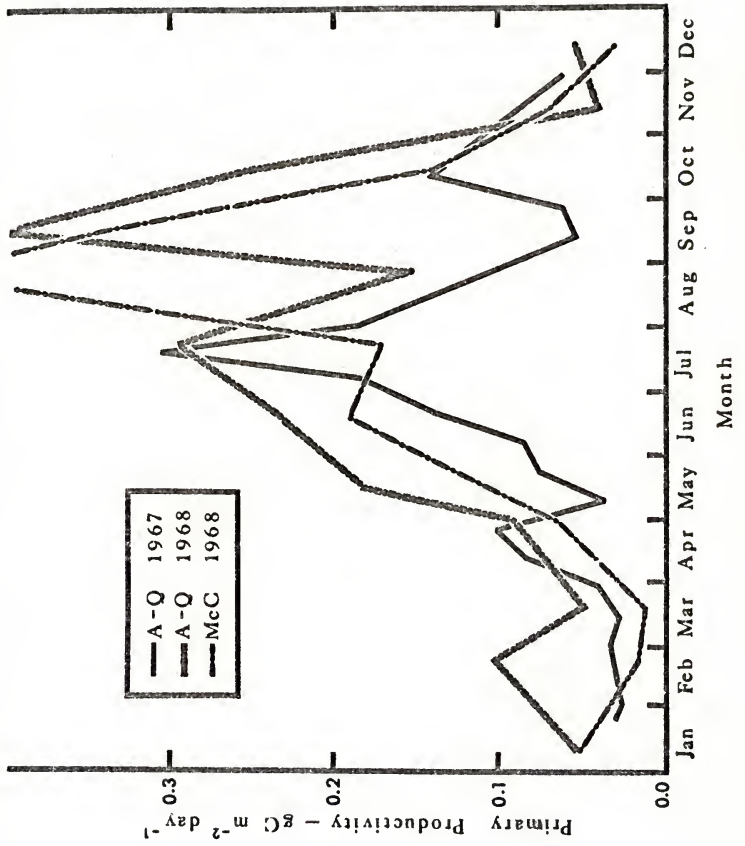




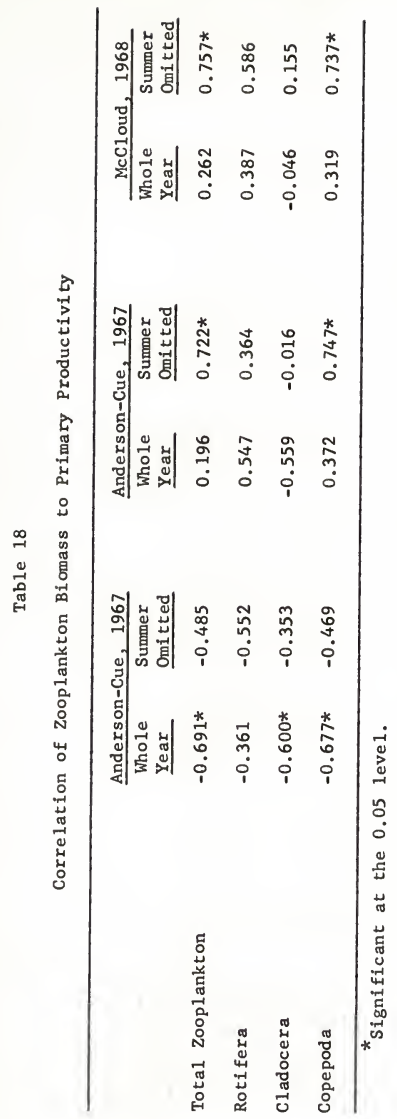


the whole year, zooplankton biomass was a pparently unrelated to primary productivity except in Anderson-Cue, 1967, where a negative correlation existed. When the summer data were excluded, a strong positive correlation between zooplankton biomass and primary productivity was found in each case (except Anderson-Cue, 1967, where no significant correlation existed). However, when the zooplankton were broken up into groups only the copepods showed a strong relationship to primary productivity. Primary productivity and temperature are strongly related (Table 19), with variations in temperature accounting for 57-75 percent of the variation in primary productivity.

Table 19

Relationship between Temperature and Primary Productivity

\begin{tabular}{cc}
\hline \multicolumn{1}{c}{ lake-year } & $\frac{\text { rvalue }}{\text { Anderson-Cue, 1967 }}$ \\
Anderson-Cue, 1968 & 0.757 \\
McCloud, 1968 & 0.865 \\
\hline
\end{tabular}

Since photoperiod could influence primary productivty and zooplankton reproduction, correlation coefficients for photoperiod compared to primary productivity and zooplankton biomass were calcuated (Table 20). The correlation of primary productivity with photoperiod was not as good as the correlation with temperature. Zooplankton biomass is unrelated to photoperiod. 
Table 20

Correlation Coefficients for Photoperiod Compared to Primary Productivity and Zooplankton Biomass

\begin{tabular}{|c|c|c|c|}
\hline & $\begin{array}{c}\text { Anders on-Cue } \\
1967 \\
\end{array}$ & $\begin{array}{c}\text { Anders on-Cue } \\
1968 \\
\end{array}$ & $\begin{array}{c}\text { McCloud } \\
1968 \\
\end{array}$ \\
\hline Primary Productivity & $0.612 *$ & $0.623 *$ & 0.525 \\
\hline $\begin{array}{l}\text { Zooplankton Biomass } \\
\text { (Summers omitted) }\end{array}$ & 0.036 & 0.040 & 0.323 \\
\hline
\end{tabular}

\section{Species Interactions}

Among fresh-water zooplankton, at any given time, one member of a group will tend to be dominant in the group (Pennak, 1957). In this study the strength of dominance among cladocera was tested both in terms of numerical dominance and biomass dominance (Tables 21-23). Dominance is expressed as the percent of the total cladoceran numbers (or biomass) which is made up by that species having the greatest numbers (or biomass). No one cladoceran was dominant at all times but usually the dominant species tended to remain dominant for several weeks .

It was usual to find three or four cladoceran species in a sample. Samples containing only two species comprised just 20 percent of the total observations and under two species were found in only two samples (in which no cladocera were found). The mean percents comprised by the dominant when different numbers of species were present (Table 21) show a tendency for one species, the dominant, to be much more common than would be expected by chance. If there were no dominance, one would 
Table 21

Numerical Dominance of Cladocera When Different Numbers of Species Were Present

\begin{tabular}{lccc}
\hline Number of Species Present & 2 & 3 & 4 \\
Mean \% Comprised by Dominant & 81 & 72 & 65 \\
\% of Total Samples & 19.5 & 52.2 & 28.3 \\
\hline
\end{tabular}

Table 22

Numerical Dominance of Cladoceran Species

D. ambigua $\underline{B}$. coregoni D. brachyurum $\underline{H}$. amazonicum

$\%$ of cladoceran

$\begin{array}{lllll}\% \text { of Time Dominant } & 40 & 46 & 13 & 0\end{array}$

$\%$ of Time Above

$25^{\circ} \mathrm{C}$ Dominant $20 * \quad 64 * \quad 12 \quad 0$

${ }^{*}$ Significantly different from above figure (0.05 leve1).

Table 23

Biomass Dominance of Cladoceran Species

D. ambigua B. coregoni D. brachyurum H. amazonicum

$\%$ of Cladoceran

$\begin{array}{llll}\text { Biomas s when Dominant } & 75 & 67 & 58\end{array}$

$\begin{array}{lllll}\% \text { of Time Dominant } & 64 & 22 & 10 & 4\end{array}$

$\%$ of Time Above

$25^{\circ} \mathrm{C}$ Dominant $\quad 45 * \quad 39 * \quad 11 \quad 0$

`Significantly different from above figure (0.05 level). 
expect that, when two species were present, each would make up about 50 percent of the tota1; three, 33 percent; four, 25 percent.

Dominance may also be considered in terms of different species and different seasons (Tables 22,23). D. ambigua and B. coregoni were most likely to be dominant, being numerically dominant in about an equal number of samples. Blomass dominance does not correspond exactly to numerical dominance; in terms of mass, larger species tend to be dominant a greater proportion of the time than in terms of numbers. In terms of biomass, D. ambigua was the species most likely to be dominant at any time.

Whether considered in terms of numbers or biomass, B. coregoni was more likely to be dominant at warmer temperatures than at colder temperatures, while $\underline{D}$. ambigua was more likely to be dominant at colder temperatures. To check the nature of this shift in dominance, all data were pooled and the mean biomasses of D. ambigua and B. coregoni below and above $25^{\circ} \mathrm{C}$ were calculated (Table 24). The change in dominance is due to a significant decrease in D. ambigua, while B. coregoni is unaffected.

Table 24

Relationship of Temperature to Daphnia and Bosmina Biomass

\begin{tabular}{lcc}
\hline & $\begin{array}{c}\text { Mean Biomass }\left(\mathrm{mg} / \mathrm{m}^{2}\right) \\
\text { Below } 25^{\circ} \mathrm{C}\end{array}$ & $\frac{\text { Above } 25^{\circ} \mathrm{C}}{38.9}$ \\
$\underline{\text { B. ambigua }}$ & $\frac{108.5}{21.8}$ & 25.1 \\
\hline
\end{tabular}




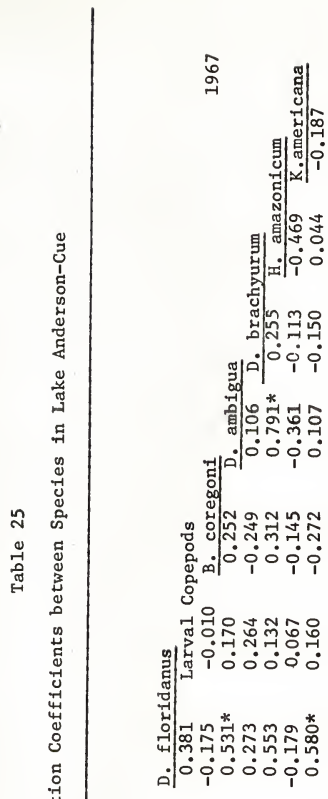

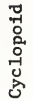

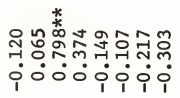

齐

$\infty$
$\stackrel{్}{\circ}$
ᄀ్-

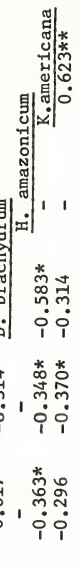

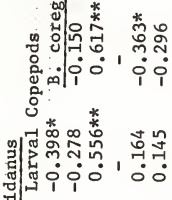

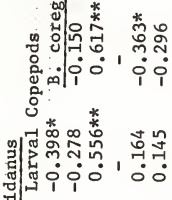

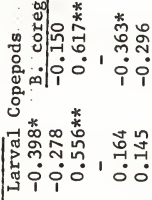

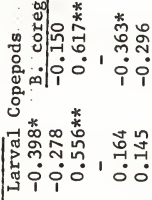

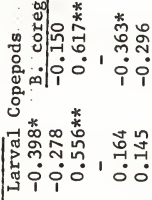

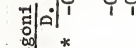

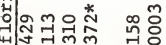

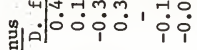

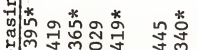
:ी०००0001

ㄷํㅇㅇㅇ

$\checkmark \stackrel{*}{m} \infty \stackrel{*}{N}$ an

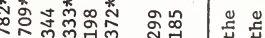

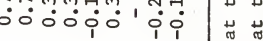

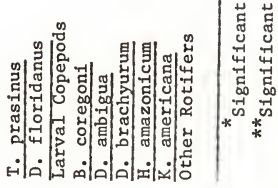



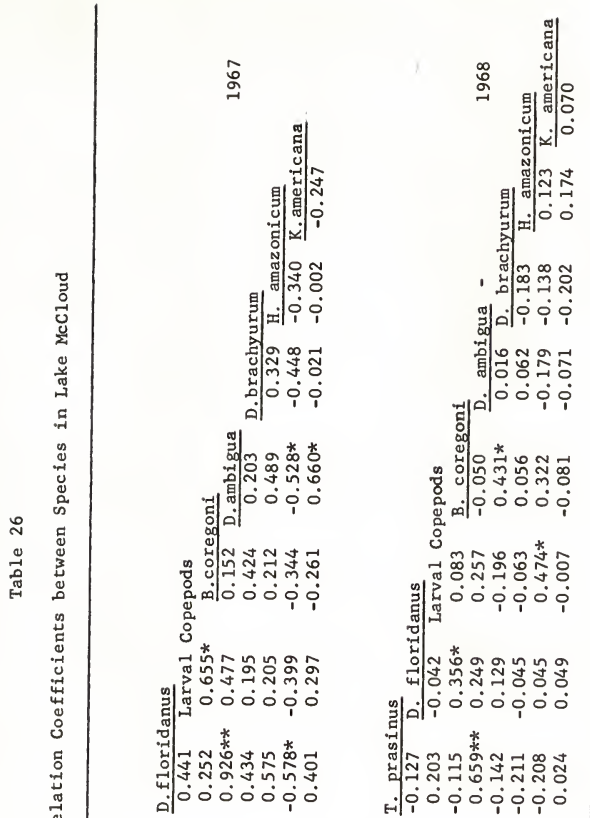

혱

๓

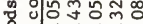

¿. ㅇํㅇ

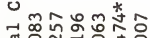

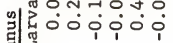
矛覀

.-1

닌 or on n in a I 光| 先

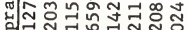
Hili

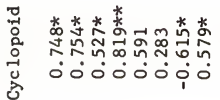

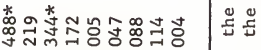

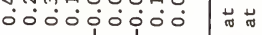
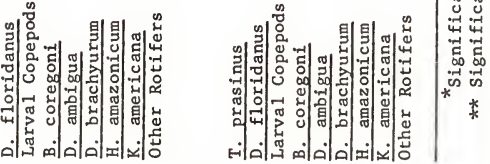


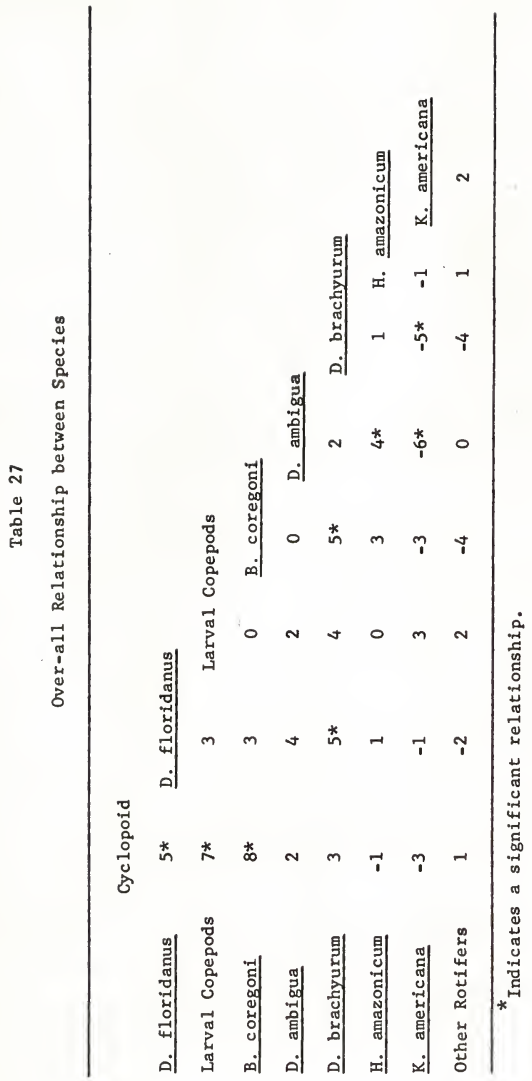


If two species were strong competitors over a period of time during which environmental conditions were gradually changing--first favoring one, then the other--one would expect to find a negative correlation between them. On the other hand, if two species were not competing and were favored by similar environmental conditions such as temperature, one would expect them to be positively correlated. To test for such relationships, correlation coefficients were calculated for every combination of major zooplankton species in the lakes (Tables 25, 26). The resulting data were difficult to analyze since two species which were significantly correlated in one lake-year might be unrelated in other lake-years. To simplify the results, they were scored as follows:

Any positive but not significant correlation received a score of plus one.

A positive correlation significant to the 0.05 level recelved plus two.

A positive correlation significant to the 0.001 level received plus three.

Negative correlations were scored the same way except that minus values were awarded.

The scores from all lake-years were then added algebraically (Table 27). In interpreting the results a score of $>+4$ or $<-4$ was considered to show a significant relationship since \pm 4 could be achieved by chance (probability of \pm 4 equals 0.07 ). Analyzed in this way, the zooplankton seem to fall into three groups: 


$\begin{array}{lll}\text { D. floridanus } & \text { D. ambigua } & \text { Rotifers } \\ \text { M. edax } & \text { H. amazonicum } \\ \text { T. prasinus } & \\ \text { B. coregoni } & \\ \text { D. brachyurum } & \end{array}$

Groups I and II seem to be independent while group III tends to be negatively correlated with both of the other two groups.

Correlation coefficients were also calculated between taxonomlc groups (Table 28). Copepod biomass shows a significant positive correlation to cladoceran biomass in all lake-years, but no relationship to rotifer biomass. Cladocera and rotifers gave a significant, but low, negative correlation in Anderson-Cue, 1968, being unrelated in other 1ake-years.

Table 28

Correlations between Biomass of Taxonomic Groups

\begin{tabular}{lrcc}
\hline & $\begin{array}{c}\text { Copepoda } \\
\text { to } \\
\text { Cladocera }\end{array}$ & $\begin{array}{c}\text { Copepoda } \\
\text { to } \\
\text { Rotifera }\end{array}$ & $\begin{array}{c}\text { Cladocera } \\
\text { to } \\
\text { Rotifera }\end{array}$ \\
\hline Anderson-Cue, 1967 & $0.698 * *$ & 0.342 & -0.066 \\
McCloud, 1967 & $0.965 * *$ & 0.339 & 0.334 \\
Anderson-Cue, 1968 & $0.320 *$ & -0.190 & $-0.492 *$ \\
McCloud, 1968 & $0.313 *$ & -0.092 & -0.088 \\
\hline *Significantlydifferent from zero at the 0.051 level. \\
** Significantly different from zero at the 0.001 level.
\end{tabular}


Production

The calculated yearly production by each species is shown in Table 29. Estimates of yearly primary production as determined by the Environmental Engineering staff along with the "best estimate" of secondary production and secondary efficiency are shown in Table 30 . For conversion of $\mathrm{gC}$ to $\mathrm{g}$ dry weight organic matter, dry organic matter was assumed to be 50 percent carbon. Secondary production includes production by all species of zooplankton except Mesocyclops edax which, being carnivorous, belongs to the next trophic level.

\section{Predation}

The population of Labidesthes sicculus in Lake Anderson-Cue was estimated in late fall of 1967. On 25 and 26 November a total of 901 L. sicculus were captured, fin clipped, and released in the lake. On 1 December, 2,018 L. sicculus were captured, 13 of which were recaptures, From these data the population of $\underline{L}$. sicculus was calculated (using formulas from Ricker, 1958) to be 130,000 with a 95 percent confidence interval of 86,000 to 260,000 .

The gut contents of $47 \mathrm{~L}$. sicculus are reported in Table 31 . During December, when the population was estimated, nearly all $\underline{\mathrm{L}}$. sicculus were over $25 \mathrm{~mm}$ long. The mean zooplankton consumption for fish above $25 \mathrm{~mm}$ was $267 \mu \mathrm{g}$. On this basis $130,000 \mathrm{fish}$ would consume $34.7 \mathrm{~g}$ of zooplankton per unit time, where the time unit involved is that time necessary for an ingested plankter to digest beyond a recognizable state (1.e., clearance time). Unfortunately no determinations of clearance time were made in this study. To get an idea of predation pressure a minimum clearance time was needed. Bokova (1940) gave a value of 10 


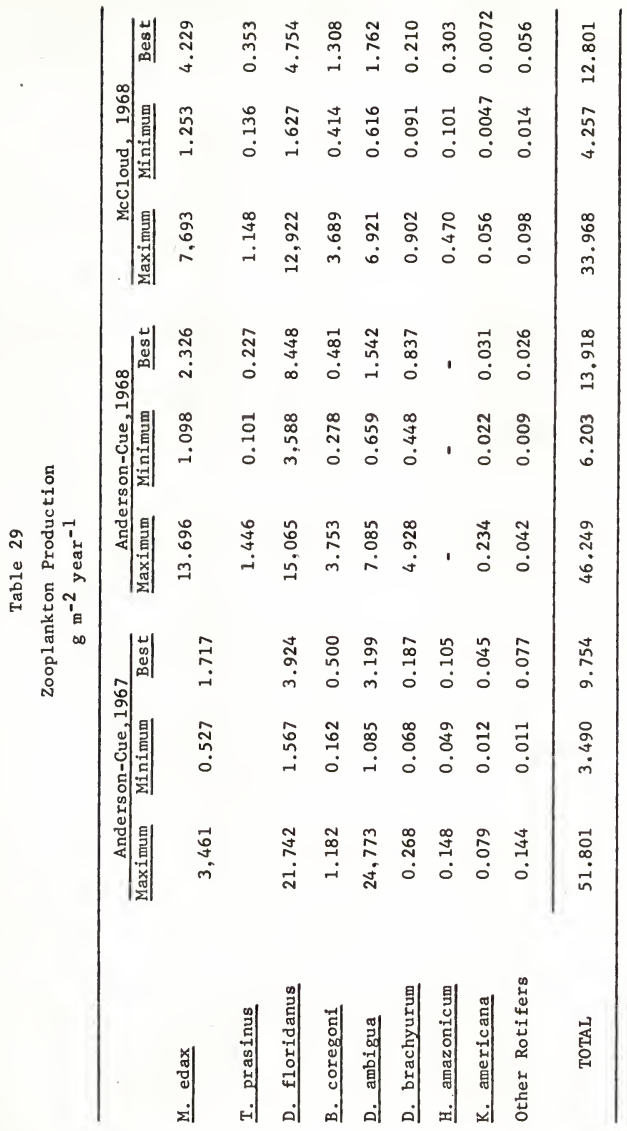




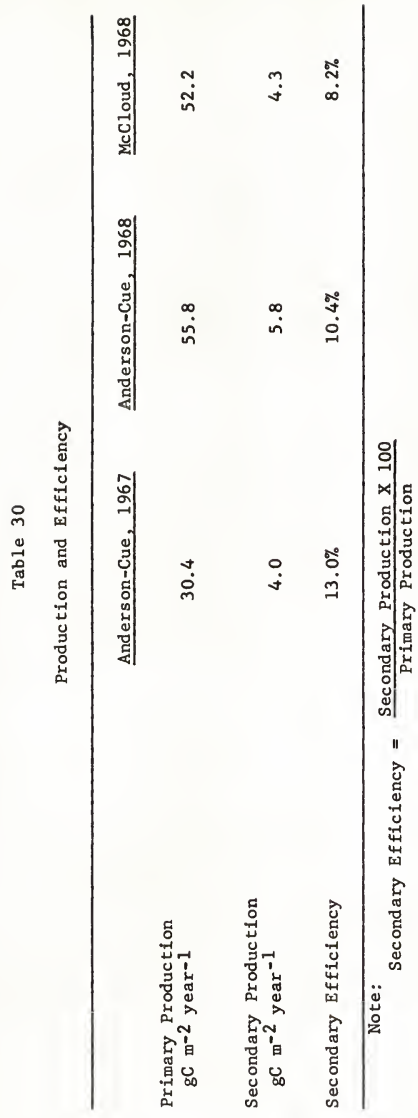


hours for clearance time at $20-26^{\circ} \mathrm{C}$ for the roach, Rutilus rutilus. Assuming a maximum temperature of $30-35^{\circ} \mathrm{C}$ and $\mathrm{Q}_{10}$ of 3.0 a minimum clearance time of ca. 3 hours is obtained. Since L. sicculus feeds only during daylight this minimum clearance rate is approximately onefifth of a feeding day. Maximum daily consumption would then be five times the observed gut contents, or $174 \mathrm{~g}$ of zooplankton for the entire population. This value can be compared to the mean biomass of zooplankton in Anderson-Cue over the two years, $493 \mathrm{mg} / \mathrm{m}^{2}$. Since the surface area of the lake is ca. 7.85 hectares, there would be $38.7 \mathrm{~kg}$ of zooplankton in the 1ake. Thus the L. sicculus population would be able to consume ca. 0.4 percent of the standing crop of zooplankton in one day. The yearly zooplankton production in Anderson-Cue was $929 \mathrm{~kg}$. At the rate calculated above, L. sicculus would consume $63 \mathrm{~kg} /$ year or ca 7 percent of the zooplankton production.

Table 31

Gut Contents of $\underline{\text { L. Sicculus }}$

Length Range (mm) Zooplankton Consumed ( $\mu \mathrm{g}) \quad \underline{\text { Number in Sample }}$

$$
15.01 \pm 2.01
$$

11

$25-35$

$190.3 \pm$

85.6

6

$35-45$

$282.9 \pm 193.0$

4

$45-55$

$209.6 \pm 67.2$

10

$55-65$

$359.8 \pm 88.0$

7 


\section{DISCUSSION}

Population Dynamics

In Florida's mild climate, reasonably shallow oligotrophic lakes such as those studied furnish a remarkably stable physical environment for plankton. The maximum yearly temperature fluctuation in AndersonCue and $\mathrm{McCl}$ oud was $20^{\circ} \mathrm{C}$ (from $12-32^{\circ} \mathrm{C}$ ). The maximum observed temperature difference between surface and bottom was $3^{\circ} \mathrm{C}$, but it was usually less than $1^{\circ} \mathrm{C}$. The water is continually mixed by wind action so that stratification of nutrients cannot occur. Sunlight typically penetrates to the bottom. In general, the physical environment varies only gradually with seasonal temperature and photoperiod changes.

By direct contrast the biological community is not at all stable; primary productivity, chlorophyl1 concentration, and zooplankton biomass vary by more than an order of magnitude; while species populations of both algae and zooplankton may vary by five or more orders of magnitude. Populations in natural ecosystems have traditionally been considered as being in equilibrium with their environment and changing only in response to some environmental change. Quite obviously the biotic community in these lakes is not in equilibrium with the physical environment.

Slobodkin (1954) demonstrated that a fairly long time period, on the order of 40 days, is required for a single cladoceran species, Daphnia obtusa, to reach an equilibrium population in a constant laboratory environment and has suggested that natural populations may never reach 
equilibrium before further environmental changes occur. In the light of the present study several additions may be made to Slobodkin's hypothesis. First, in a mixed culture or natural community the environment of any one species includes all of the other species as well as the physical parameters. If some environmental change occurs, all populations will tend to adjust to the new conditions. The adjustment is not instantaneous but requires a time period of at least one and probably several generations. As any one species population changes in adjustment to the environment it will automatically alter the environments of all other species. Thus the time required for a community to equilibrate is greatly extended. If other changes should occur before equilibrium is reached, the community will be in perpetual nonequilibrium. Forces will always be present pushing the populations toward equilibrium, but equilibrium $\mathrm{c}$ an never be attained, since the equilibrial size of any population will be constantly changing.

Demonstration of cause-effect relationships between environmental variables and population size or group biomass is difficult because of the nonequilibrial nature of the relationship, as we 11 as the lag response described by Slobodkin (1954) and Edmondson (1965). The 1ag period necessary for any species population to adjust to an environmental change is dependent on the generation time for that species, which in turn is dependent upon temperature and food (Ingle, et a1., 1937; Hazelwood and Parker, 1961; Elbourne, 1966). Accordingly, no two species can be expected to have the same lag time, and lag time for any one species will not be constant. Even if variations in a single environmental factor are responsible for changes in zooplankton biomass, 
correlation of biomass with the particular factor may be poor. Comparison of taxonomic groups, or even separate species, with environmental factors should give truer correlations but even these will be blurred by variations in time lag with environmental changes.

As previously mentloned, the niche diversity for zooplankton in lakes like those studied must be very low. The lack of thermal stratification permits no diversity on that basis. Cover and substrate are uniform throughout the water column. The available foods--algae and bacteria--range somewhat in size, permitting three possible divisions with considerable overlap: large raptoral feeders, small raptoral feeders, and filter feeders. The possibility of further dividing these could admit perhaps six niches in the zooplankton. Why, if the competitive exclusion principle (Hardin, 1960) holds, are there more than six species of zooplankton in a lake at one time?

To begin with, there are relatively few species of open-water zooplankton. These same lakes contain ca. 25 species of littoral cladocera but only four species are found in the open water. Still the question remains, why should there be even four? All the limnetic cladocera in these lakes are filter feeders (Hutchinson, 1967); all are about the same size--from one to five micrograms--and all were found together in the plankton about 28 percent of the time. At least three cladoceran species were found in 80 percent of the samples taken. Are they competing and, if so, why are not all but one eliminated? Different genera of cladocera and even cladocera and copepods have been shown to be unable to coexist in laboratory cultures (Frank, 1952, 1957; Parker, 1960, 1961). 
The correlation coefficients between populations of the different cladocera showed no tendency for any species to decline while any other species was increasing. On the contrary, some showed positive correlations (D. ambigua to H. amazonicum; B. coregoni to D. brachyurum). The pattern of dominance in cladocera, however, showed that a given set of environmental conditions might be distinctly more favorable to one specles than to another. Even though two species were positively correlated, dominance of one over the other at a given time was almost certain. In the summer of 1968 in Anderson-Cue, all cladocera disappeared from the lake for a short time. As they began to come back, three species were seen (Figure 10). B. coregoni and D. ambigua appeared together, with both populations increasing rapidly but Bosmina increased more rapidly than Daphnia, exceeding it in numbers by an order of magnitude as both populations began to level of $f$. D. brachyurum appeared about two weeks later than the other two but multiplied at a rate nearly equivalent to Bosmina's initial rate and soon achieved a population roughly equal to Bosmina. The Bosmina population then decreased by about an order of magnitude while Diaphanosoma decreased only slightly, thus acquiring dominance.

The above example shows two things. First, competition probably exists between these species. Second, the effects of competition can be obscured by changes in the environment. When cladocera started to come back into the system all three were favored, just as populations of two or more species inoculated into a new medium would increase initially before competition became important. After the populations , reached a "normal" level a distinct tendency for one to dominate was displayed. 
Figure 10. Population fluctuations of cladocera in Lake Anderson-Cue following their summer disappearance in 1968. 


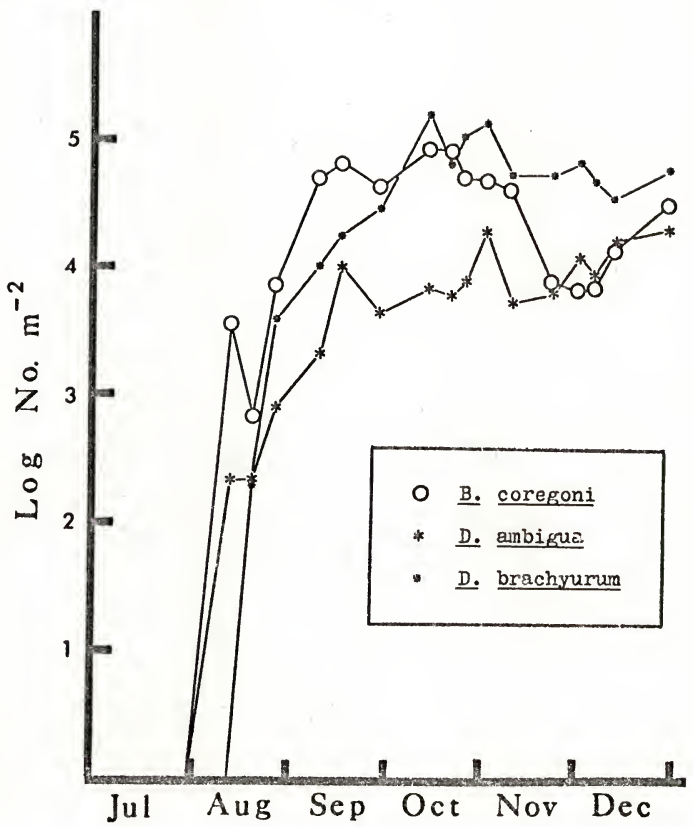


The presence of competition but not competitive exclusion is explained by the nonequilibrium nature of the ecosystem. If an equilibrium is reached, the outcompeted species will be eliminated, but environmental changes effectively give the losing species a new start. If the environment is sufficiently transitory, species which would compete strongly in a laboratory culture may show a distinctly positive correlation. In the event that biological equilibrium should be reached, causing exclusion of some species, nearly all fresh-water plankters have some sort of resting stage which allows them to develop a new population at a later time (Hutchins on, 1967).

The smaller coefficients of variation for groups as compared to species and the better interlake correlation of total and group biomass as compared to species biomass (Table 15) indicate that factors acting to control the populations are acting on the whole trophic level rather than on individual species. The good correlation $(r=0.686)$ between zooplankton biomass in the two lakes indicates that climatic factors (1. e., factors which would affect both lakes) play a large part in regulating zooplankton populations, but the mechanism for action of climate on zooplankton is not intuitively obvious.

While the summer decline was statistically significant in both lakes, the reason it occurred is less easily demonstrated. When the summer data were ignored the zooplankton blomass followed the temperature curve. A possible explanation for the summer drop would be that temperature had passed the optimum for species present. However, zooplankton biomass returned to normal and, indeed, to its highest value while temperature was still above the level of the initial drop. Also the recovery from the summer low began while temperature 
was at maximum. The summer low could not be due to lack of food because both primary productivity and chlorophyll concentration were higher during the summer.

A study of the reactions of individual species to the summer discontinuity provides an insight into its cause. Only the larger zooplankters showed a significant decline during the summer. Intermediate species showed essentially no response, while very small species such as the rotifers increased significantly. Also, rarer species of rotifers were much more likely to be seen during the summer biomass low. A further clue is provided by the fact that larval copepods did not decline: they even increased slightly. Evidently conditions were favorable for copepod reproduction since fewer adults were able to produce as many or more young. Accordingly the decline in adults must have been due to an increased death rate. This in turn points to an increased predation rate in summer with apparent selection for the larger forms producing results similar to those described by Brooks and Dodson (1965).

An explanation for increased predation during summer is readily available: Labidesthes sicculus and Lepomis macrochirus are spawning and the young of both are much more dependent upon zooplankton than are the adults. Hubbs (1921) and Werner (1969) have discussed the migration of fry of these species into the limnetic zone where they feed upon zooplankton, particularly microcrustacea. McLane (1955) reported that in Florida $\underline{L}$. sicculus spawns throughout the summer while $\mathrm{L}$. macrochirus spawns from May to October with most intensive spawning in June. Since the bluegill fry spend ca. 1.5 months in the limnetic zone (Werner, 1969), their period of heaviest predation falls exactly 
during the summer zooplankton low. The briefer summer decline in Anderson-Cue, 1968, as opposed to 1967 or McCloud, 1968, also supports the predation mechanism; the $\underline{L}$. sicculus population in Anderson-Cue, 1968, for some unknown reason, was very much reduced by comparison with the 1967 population or the McCloud population.

When the period of summer decline is ignored, total zooplankton biomass is closely correlated with both temperature and primary productivity. Since temperature and primary productivity are strongly correlated throughout the year, it seems reasonable that the influence of climate on zooplankton biomass, as evidenced by the close correlation between lakes, is due to two principal factors, neither of which acts directly on the zooplankton. 1. Temperature limits primary production (given a reasonably constant nutrient supply), thus limiting the food available to zooplankton and, accordingly, the zooplankton during most of the year. 2. The onset of fish reproduction, with its concomitant predation surge, is determined by climatic factors, such as temperature and photoperiod, and thus is synchronized in both lakes.

In these lakes zooplankton as a group is food-limited during most of the year. During that period competition for food should be important. In the summer, however, when zooplankton biomass is at its lowest and primary productivity is at its highest, no competition for food should exist. Thus the summer is the period when the rotifers, relatively predation immune due to their small size, develop their largest populations. Also several rarer spectes of rotifers are much more common during the summer. Their apparent relationship to temperature (Table 18) merely reflects their reaction to the decreased competition during 
the summer. The same general explanation pertains to the change in frequency of Daphnia and Bosmina dominance with warm temperatures. Temperature is not directly involved; Daphnia, being larger, receives greater predation pressure than Bosmina.

\section{Secondary Production}

The estimations of secondary production and efficiency are, admittedly, very rough. The range from minimum to maximum estimate covers about an order of magnitude. However the ranges for the 1968 values are reduced from that for 1967, probably reflecting the greater accuracy obtained with more frequent sampling. The range of efficiencies determined includes from a reasonably low efficiency to one impossibly high (Table 29). The efficiencies associated with the "best estimate" (Table 30) are in line with the general ecology efficiency of 8-12 percent (Slobodkin, 1968).

An advantage of this method of estimating zooplankton production is that contributions made by each species or higher taxonomic group can be assessed. Thus in both Anderson-Cue and McCloud, 1968, copepods accounted for ca. 75 percent of the production, cladocera contributed ca. 24 percent, and rotifers only ca. 0.5 percent. The relatively small size of rotifer species present coupled with their sporadic occurrence accounted for their low contribution to production.

There have been a few previous determinations of aquatic secondary production. As pointed out in the introduction, most of these were only rough estimates. The most important studies are summarized in Table 32. For comparative purposes all values are listed as originally reported and then as converted to $\mathrm{kcal} \mathrm{m}^{-2} \mathrm{year}^{-1}$. of the previous workers 


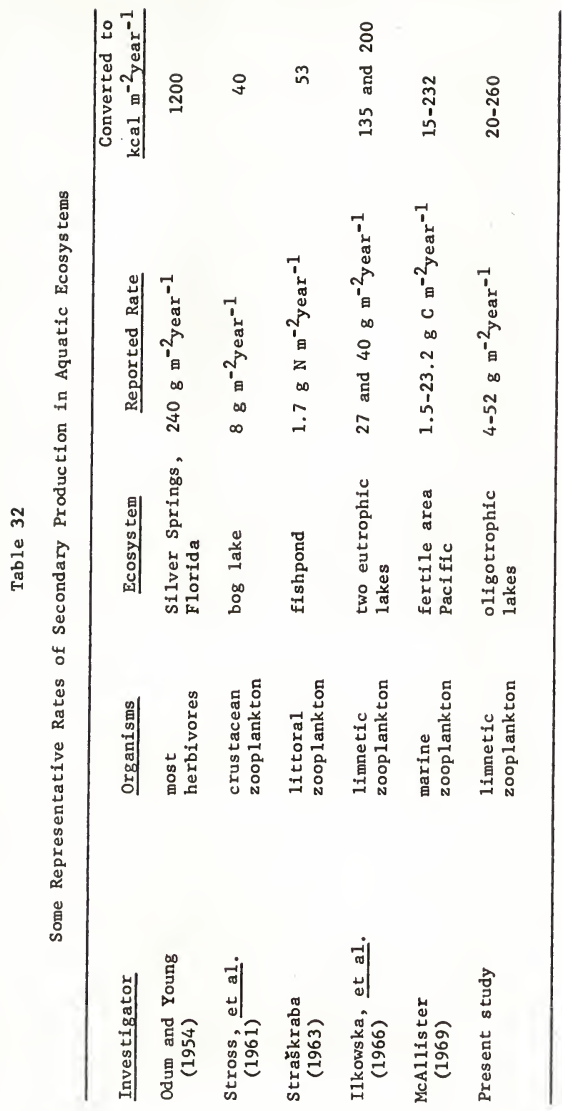


only McAllister reported any boundaries to production. The range of values from the present study is quite similar to that reported by McAllister and includes all of the other values for standing fresh waters. The "best estimate" of mean annual zooplankton production in Lakes Anderson-Cue and $\mathrm{McCl}$ oud is ca. $50 \mathrm{kcal} \mathrm{m}-2$. As one would expect for oligotrophic lakes, this value lies toward the low side of the range for standing waters.

\section{Eutrophication Effects}

The effects of eutrophication on the zooplankton have been gradual and usually indirect, but some have been noticeable enough to record. One of these is the apparent change in frequency of occurrence of rarer species (Table 11). No differences in frequency were found between Anderson-Cue, 1967, and McCloud, 1968, which suggests that Lake McCloud in 1968 was essentially the same as Anderson-Cue (and presumably McCloud) in 1967 before the effects of fertilization became noticeable. In every case where a significant difference occurred between lakes in 1968, a significant difference also occurred between 1967 and 1968 in Anderson-Cue. These changes in Anderson-Cue between 1967 and 1968 may be presumed to be due to the addition of nutrients.

With the exception of D. brachyurum, whose biomass increased significantly from 1967 to 1968 in Anderson-Cue, the normal variation in biomass was great enough to prevent minor changes in mean biomass from being significant. Nonsignificant changes did occur in AndersonCue, almost all of which were positive (Table 12). Zooplankton production also increased slightly as reported for fertilization experiments by Glonti and Tskhomelidze (1963). This trend toward increasing 
secondary biomass and secondary production will probably continue, at least for a time, as the lake becomes more eutrophic. One cannot make this conclusion from the insignificant increases observed but the community structure lends additional support. Considering the general link of zooplankton biomass to primary productivity and primary productivity to nutrients, an increase in nutrients should result in an increase in secondary production as long as the community undergoes no major structural changes. 


\section{SUMMARY}

In this study an attempt was made to evaluate the interrelationships of zooplankton populations with environmental factors in two Florida sandhills lakes. The most important conclusions are:

1. Natural zooplankton populations are not in equilibrium with their environment.

2. Competition probably occurs between simflar species of zooplankton living in the same lake, but this competition is masked by the transient nature of the environment.

3. In these lakes zooplankton is food-1imited during most of the year but predator-limited during summer.

4. Climatic factors such as temperature and light regulate primary productivity and the onset of fish reproduction, thus indirectly regulating zooplankton biomass by way of food supply and predation.

5. The mean estimate for secondary production in these lakes, $50 \mathrm{kcal} \mathrm{m}^{-2}$ year $^{-1}$, lies toward 
the low end of the range for standing

waters as one would expect for oligotrophic

1akes.

6. During the two years of this study the effects of eutrophication on the zooplankton have been slight. 


\section{LITERATURE CITED}

Anonymous. 1968. Factors affecting the present and future quality of Florida surface water. Environmental Engineering Department, Engineering and Industrial Experiment Station, University of Florida, Gainesville, Florida.

Bokova, E. N. 1940. The consumption and assimilation of food by the roach. Trans. Inst. Fish. USSR, 11.

Borecky, G. W. 1956.. Population density of the limnetic cladocera of Pymatuning Reservoir. Ecology 37: 719-727

Brooks, J. I, and Dodson, S. I. 1965. Predation, body size and composition of plankton. Science 150: 28-36.

Chemyr, V. D. 1966. Radiocarbon method of determining the production of zooplankton in a natural population. Doklady Akademii Nauk SSSR 173: 201-203.

Comita, G. W. and Anderson, G. C. 1959. The seasonal development of a population of Diaptomus ashlandi Marsh, and related phytoplankton cycles in Lake Washington. Limno1. Oceanog. 4: 37-52.

Davis, C. C. 1954. A preliminary study of the plankton of the Cleveland Harbor area, Ohio. III. The zooplankton, and general ecological considerations of phytoplankton and zooplankton production. Ohio J. Sci. 54: 384-408.

- 1958. An approach to some problems of secondary production in the western Lake Erie region. Limnol. Oceanog. 3: 15-28.

Deevey, E. S. 1942. Studies on Connecticut lake sediment. III. The biostratification of Linsley Pond. Amer. J. Sci. 240: 233-264; 313-324.

Dunn, 0. J. 1964. Basic statistics. A primer for the biomedical sciences. John Wiley \& Sons, Inc., New York.

Edmondson, W. T. 1962. The rate of egg production by rotifers and copepods in natural populations as controlled by food and temperature, Verh, int. Verein. theor, angew. Limnol. 15: 673-675. 
Edmondson,W.T. 1965. Reproductive rate of planktonic rotifers as related to food and temperature in nature. Ecol. Mong. 35: 61-111.

Edmondson, W. T., Comita, G. W., and Anderson, G. C. 1962. Reproductive rate in copepods in nature and $i$ ts relation to phytoplankton popu1ation. Ecology 43: 625-634.

Elbourn, C. A. 1966. The life cycle of Cyclops strenuus strenuus Fischer in a small pond. J. Anim. Ecol, 35: 333-347.

Elster, H. J. 1955. Ein Beitrag zur Productionsbiology des Zooplanktons. Verh. int. Verein. theor. angew. Limno1. 12: 404-411.

Frank, P. W. 1952. A laboratory study of intraspecies and interspecies competition in Daphnia pulicaria (Forbes) and Simocephalus vetulus 0. F. Müller. Physiol. Zool. 25: 178-204.

- 1957. Coaction in laboratory populations of two spectes of Daphnia. Ecology 38: 510-519.

- 1960. Prediction of population growth form in Daphnia pulex cultures. Amer. Nat. 94: 357-372.

Frank, P. W., Boll, C. G., and Kelly, R. W. 1957. Vital statistics of laboratory cultures of Daphnia pulex DeGeer as related to density. Physio1. Zool. 30: 287-305.

Gauld, D. T. 1950. A fish cultivation experiment in an arm of a sealoch; III. The plankton of Kyle Scotnish. Proc. Roy. Soc. Edinb. B-4: 36-64.

- 1951. The grazing rate of planktonic copepods. J. Mar. Bio1. Assoc. U, K. 29: 695-703.

George, M. G. 1966. The comparative ecology of five fish tanks in Delhi, India. Hydrobiologia 27: 81-108.

Gibor, A. 1956. Some ecological relationships between phy to and zooplankton. Biol. Bul1. 111: 230-234.

Glonti, Ts. A. and Tskhomelidze, 0. I. 1963. Zooplankton pri udubrenif prudov. Tr Nauchissled Rybokhoz Sta Gruzii 8: 38-43. English abstract in Bio. Abs. 48: 620 .

Goulden, C. E. 1964. The history of the cladocera fauna of Esthwaite Water and its limnological significance. Arch. Hydrobio1. 60: $1-52$.

Ha11, D. J. 1964. An experimental approach to the dynamics of a natural population of Daphnia galeata Mendotae. Ecology 45: 94-112. 
Hardin, G. 1960. The competitive exclusion principle. Science 131: 1292-1297.

Hazelwood, D. H. and Parker, R. A. 1961. Population dynamics of some freshwater zooplankton. Ecology 42: 266-274.

Hepher, B. 1962. Primary production in fishponds and its application to fertilization experiments. Limnol. Oceanog. 7: 131-136.

Hubbs, C. L. 1921. An ecological study of the life history of the fresh-water atherine fish Labidesthes sicculus. Ecology 2: 262276 .

Hutchinson, G. E. 1967. A treatise on limnology. Vol. II. Introduction to lake biology and the limnoplankton. John Wiley and Sons, Inc., New York. 1115 pp.

Ilkowska, A. H., Gliwicz, Z., and Spodniewska, I. 1966. Zooplankton production and some trophic dependences in the pelagic zone of two Massurian lakes. Verh. int. Verein. Theor, angew. Limno1. 16: 432-440.

Ingle, L., Wood, T. R., and Banta, A. M. 1937. A study of longevity, reproduction, and heart rate in Daphnia longispina as influenced by limitation in quantity of food. J. Exper. Zool. 76: 325-352.

Krishnamoorthi, K. P. and Visvesvara, G. 1963. Hydrobiological studies with special reference to fish mortality. Hydrobiologia 21: 275-303.

- 1966. Hydrobiological studies in Gandhisagar (Jumma Tank). Seasonal variations in plankton (1961-62). Hydrobiologia 27; 501-514.

Laessle, A. M. 1958. The origin and successional relationship of sandhill vegetation and sand-pine scrub. Ecol. Monog. 28: 361-387.

Lang, K. 1931. Faunistisch oklogische Untersuchungen in einigen seichten oligotrophen bzw.dystrophen Seen in Sudschweden. Lunds Univ. Arsskrift N. F. Ard. II, 27: 1-173.

Martin, J. H. 1965. Phytoplankton-zooplankton relationships in Narragansett Bay. Limnol. Oceanog. 10: 185-191.

McAllister, C. D. 1969. Aspects of estimating zooplankton production from phytoplankton production. J. Fish. Res. Bd. Can. 26: 199-220.

McLane, W. M. 1955. The fishes of the St. Johns River System. Ph. D. dissertation. University of Florida, Gainesville, Florida." 
Mendenha11, W. 1967. Introduction to probability and statistics. Second edition. Wadsworth Publishing Co., Inc. Belmont, Calif. $393 \mathrm{pp}$.

Ne1son, P. R. and Edmondson, W. T. 1955. Some limnological effects of fertilizing Bare Lake, Alaska. USFWS Fish. Bul1. 56: 415-436.

Odum, H. T. and Yount, J. L. 1954. Productivity of Florida springs. Second annual report to Biology Branch. Office of Naval Research.

Parker, R. A. 1960. Competition between Simocephalus vetulus and Cyclops viridis. Limnol. Oceanog. 5: 180-189.

- 1961. Competition between Eucyclops agilis and Daphnia pulex. Limnol. Oceanog. 6: 299-301.

Pennak, R. W. 1946. The dynamics of fresh-water plankton populations. Ecol. Monog, 16: 339-355.

- 1949. Annual limnological cycles in some Colorado reservoir lakes. Ecol. Monog. 19: 233-267.

- 1957. Species composition of limnetic zooplankton communities. Limnol. Oceanog. 2: 222-232.

Pennington, W. 1941. The control of numbers of fresh-water phytoplankton by sma11 invertebrate animals. J. Ecol. 29: 204-211.

Pratt, D. M. 1943. Analysis of population development in Daphnia at different temperatures. Biol. Bu11. 85: 116-140.

Ricker, W. E. 1958. Handbook of computations for biological statistics of fish populations. Roger Dunamel, F. R, S. C. Ottawa, Canada.

Ryther, J. H. 1954. Inhibitory effects of phytoplankton upon the feeding of Daphnia magna with reference to growth, reproduction and survival. Ecology 35: 522-533.

Shushkina, E. A. 1966a. The estimation of zooplankton production in different lakes. Verh. int. Verein. theor. angew. Limnol. $16: 419-424$.

- 1966b. Sootnoshenie produktsii i biomassy zooplanktona ozer. Gidrobio1. Zh. 2: 27-35.

Slobodkin, L. B. 1954. Population dynamics in Daphnia obtusa Kurz. Eco1. Monogr. 24: 69-88.

- 1968. How to be a predator. Am. Zoologist 8: 43-51. 
Smith, F. E. 1963. Population dynamics in Daphnia magna and a new model for population growth. Ecology 44: 65 $\overline{1-663}$.

Straškraba, M. 1963. Share of the littoral region in the productivity of two fishponds in Southern Bohemia. Rospravy CSAV, rada MPV, 73, 13: $63 \mathrm{pp}$.

Stross, R. G. and Hasler, A. D. 1960. Some lime induced changes in lake metabolism. Limnol. Oceanog. 5: 265-272.

Stross, R. G. Neess, J. C., and Hasler, A. D. 1961. Turnover time and production of planktonic crustacea in limed and reference portion of a bog lake. Ecology 42: 237-245.

Ward, E. B. 1940. A seasonal population study of pond entomostraca in the Cincinnati region. Amer. Nat. 23: 635.

Werner, R. G. 1969. Ecology of 1imnetic bluegill (Lepomis macrochirus) fry in Crane Lake, Indiana. Amer. Nat. 81: 164-181.

Wright, J. C. 1958. The 1imnology of Canyon Ferry Reservoir. I. Phytoplankton - zooplankton relationships in the euphotic zone during September and October, 1956. Limnol. Oceanog. 3: 150-159. 


\section{BIOGRAPHICAL SKETCH}

Paul E. Maslin was born Apri1 5, 1943, in Newcastle, Pennsylvania. He was graduated from Bushnell High School in May, 1961. In the following September he entered the University of Florida, from which he received the degree of Bachelor of Science with a major in Biology. In May, 1965, he began graduate work in the Department of Zoology at the University of Florida. He worked as a teaching and research assistant for a year, then received a traineeship grant through the Department of Environmental Engineering. From May, 1967, when he was granted permission to bypass the master's degree, until the present time, he has pursued his work toward the degree of Doctor of Philosophy.

Mr. Maslin is married to the former Karolyn Regina Johnston. He is a member of Phi Sigma, The American Society of Limnology and Oceanography, and The American Association for the Advancement of Science. 
This dissertation was prepared under the direction of the chairman of the candidate's supervisory committee and has been approved by al1 members of that committee. It was submitted to the Dean of the College of Arts and Sciences and to the Graduate Council, and was approved as partial fulfillment of the requirements for the degree of Doctor of Philosophy. September, 1969.

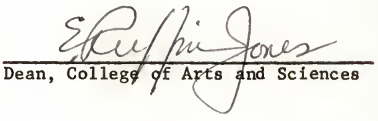

Dean, Graduate School

Supervisory Committee:

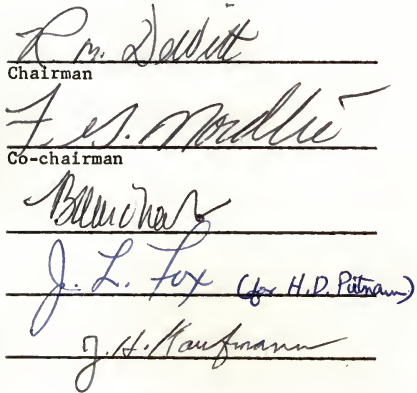

